\title{
Regional Labor Market Adjustments in the United States
}


Regional Labor Market Adjustments in the United States

Mai Dao, Davide Furceri, and Prakash Loungani 


\title{
IMF Working Paper
}

Research Department

\section{Regional Labor Market Adjustments in the United States \\ Mai Dao, Davide Furceri, Prakash Loungani ${ }^{1}$}

November 2014

\section{This Working Paper should not be reported as representing the views of the IMF.} The views expressed in this Working Paper are those of the author(s) and do not necessarily represent those of the IMF or IMF policy. Working Papers describe research in progress by the author(s) and are published to elicit comments and to further debate.

\begin{abstract}
We examine patterns of regional adjustments to shocks in the US during the past four decades. We find that the response of interstate migration to relative labor market conditions has decreased, while the role of the unemployment rate as absorber of regional shocks has increased. However, the response of net migration to regional shocks is stronger during aggregate downturns and increased particularly during the Great Recession. We offer a potential explanation for the cyclical pattern of migration response based on the variation in consumption risk sharing.
\end{abstract}

JEL Classification Numbers: F31, F4, J30

Keywords: Interstate migration, labor mobility, regional labor markets Authors E-Mail Addresses: mdao@imf.org; dfurceri@imf.org; ploungani@imf.org

\footnotetext{
${ }^{1}$ We would like to thank Olivier Blanchard, Larry Katz and JustinWolfers for valuable comments. Helpful feedback from participants at the 2013 SEEK conference in Mannheim, various seminars at the IMF, and the European Regional Science Association conference in Palermo is gratefully acknowledged.
} 


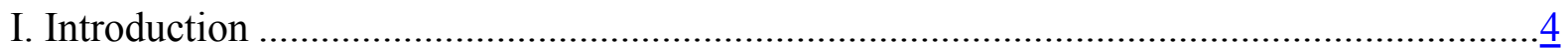

II. Statistical Properties of Regional Employment …................................................

III. Baseline Econometric Approach and Results …....................................................

IV. Endogeneity of State Labor Demand Shocks ............................................................. $\underline{8}$

A. Test of OLS Identification Assumption ....................................................

B. Validation of Results with Migration and Population Data .................................. 12

V. The Evolution of Regional Adjustment ................................................................ 14

A. Documenting Patterns of Regional Adjustment................................................

B. Regional Adjustment During Recessions and Expansions ................................ $\frac{17}{19}$

C. What Drives the Pattern of Mobility? ............................................................ $\frac{19}{19}$

Compositional Effects................................................................. 19

The Role of Risk Sharing..............................................................20

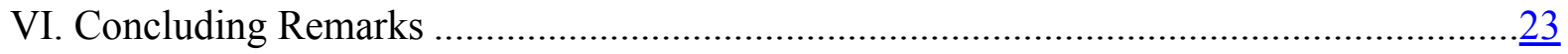

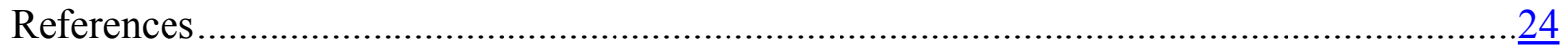

Tables

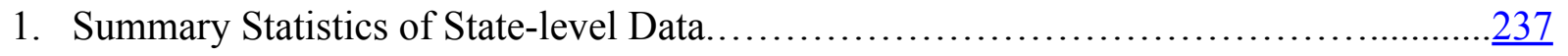

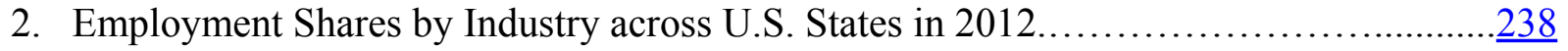

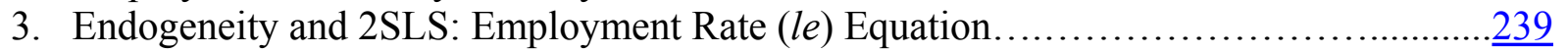

4. Endogeneity and 2SLS: Participation Rate $(l p)$ Equation...............................

5. Direct Estimation of Migration Response to Labor Market Shocks using ACS Data...... $\underline{230}$

6. Job-Related Out-migration Rate by State during the Great Recession: percent of working-age labor force overall and percent of unemployed................

7. Job-search Related Interstate Migration Rate of the Labor Force....................232

Figures

1. Persistence of Employment Growth Rates across U.S. States, 1976-2011............ 23

2. Dispersion of Employment Growth Rates across U.S. States, 1976-2011..............234

3. Response of State-relative Labor Market Variables: OLS ...........................

4. Distribution of Predicted Employment Growth Based on State-level Industry Mix....... $\underline{236}$

5. 2SLS First Stage Regression, Full Sample and Sub-samples.......................237

6. Response of State-relative Labor Market Variables: OLS vs. IV ....................238

7. Decomposition of a 1 Worker Regional Labor Demand Shock to 3 Adjustment Margins: OLS vs. IV Reduced Form...................................... 239

8. Response of Ccumulative Net Migration, Using Migration and Population Data Direct Estimates vs. VAR Identifications........................................

9. Response of Net Migration to 1 Percent State-relative Labor demand Shock: Three Sub-samples...................................................

10 Cross-sectional Correlation between Labor Demand and Net-migration: 
2007 vs. 2009.

11. Short-run Response of Net Migration to Labor Demand Shock of 1 Worker: Expanding Window Regressions. $\underline{23}$

12. Short-run Response of Migration/unemployment/participation to Labor Demand Shock of 1 Worker: Expanding Window Regressions. $\underline{234}$

13. Interstate Migration Rate: Percent of Working-age Population. .$\underline{23}$

14. Interstate Migration Rate for Job-search: Percent of Working-age Labor Force.......... 23

15. Response of State-level Relative Labor Market Variables to a 1 Percent Negative Labor Demand Shock: Business Cycle Interaction. ...

16. Response of Cumulative Net Migration to a 1 Percent Negative Labor Demand Shock: Business Cycle Interaction

17. Dynamics of Uninsured Risk: Business Cycle Interaction... $\underline{23}$

18. Response of Cumulative Net Migration to a 1 Percent Negative Labor Demand Shock: Role of Risk Sharing. 


\section{INTRODUCTION}

One of the often cited positive features of the U.S. labor market is its high degree of labor mobility, distinguishing it from labor markets in other advanced countries such as continental Europe. The seminal Brookings Paper by Blanchard and Katz (1992), henceforth BK, established some important stylized facts about how states in the US respond to regional shocks in terms of adjustment in unemployment, participation and interstate migration in the post-war period up to 1990. It concludes that interstate migration plays the most important role for adjustments to regional shocks, both in the short as well as long term, more so than regional relative wages or firm reallocation. This is in line with wide-held belief that geographic mobility in the United States is among the highest in the world.

In the two decades since the BK paper, facilitated by the availability of new sources for migration data, a large literature has developed documenting various trends in migration in the U.S. as well as other developed countries (see the review in Molloy and others, 2011). One salient trend in aggregate migration that has been widely documented is the steady and widespread reduction in (gross) internal migration rates in the U.S. since the 1980s. But did this trend in overall mobility also translate to smaller (net) migration response to regional disparities?

In this paper, we first revisit the question in the BK exercise: How have regional labor market flows, including interstate migration and regional labor supply (unemployment and participation), acted as adjustment channels to regional booms and busts in recent years? We go further than just adding 20 years to the BK exercise. Given the availability of official interstate net-migration data starting in 1990, right after the end of the BK sample, we can also directly look at the behavior of migration in response to regional and aggregate shocks, as opposed to treating it as a residual, and thus verify the BK identification assumption. Second, can one detect any shift in adjustment patterns in the last 20 years as compared to the BK findings? Particularly during the Great Recession, the interplay between high mortgage debt and the wide-spread housing bust led some policy makers (Kocherlakota, 2010) and researchers (Frey, 2009) to believe that the crisis slowed the ability of workers in hard hit regions to move to new opportunities elsewhere. We address the issue of cyclical shifts in labor mobility using various estimation techniques and datasets.

We establish several results that reveal important patterns in regional adjustment mechanisms: First, compared to the earlier sample up to 1990, the response of migration to regional shocks both in the short and long-run has decreased, while the role of unemployment and participation response has increased. That is, following the same negative shock to labor demand, affected workers have more and more tended to either drop out of the labor force or remain unemployed instead of relocating, particularly within the first two years of the shock. The new result of our paper is, however, that the sensitivity of state-relative labor force participation and unemployment versus migration to state-specific shocks has displayed strong cyclical patterns. Bad times trigger more adjustment through relocation and less adjustment through participation and unemployment in response to state-specific shocks than good times.

We go further by looking at possible determinants of the observed evolution of migration and regional labor supply in response to regional shocks. We find that the composition of the 
labor force as well as demographic characteristics of job-seekers do not explain the increased responsiveness of interstate migration during the Great Recession, as job-search related mobility increased within virtually all groups that have very different mobility rates on average. Instead, we identify the ability to smooth consumption as an important factor contributing to the countercyclicality of migration response. To this end, we first show that the ability to insure consumption against idiosyncratic risk is pro- cyclical, rising in booms while being almost absent in recessions. Furthermore, once we control for the aggregate degree of consumption risk sharing, the responsiveness of migration to regional shocks does not exhibit any counter-cyclical pattern anymore, suggesting that the ability to smooth consumption during recessions is an important determinant of the decision on whether to move in search of better job prospects. Our thorough test of the original BK identification assumption using migration data as well as instrumental variables, the derived evolution of the adjustment pattern, and in particular its variation along the business cycle are our key contributions to the literature that has built on the BK approach, such as Partridge and Rickman (2003), Beyer and Smets (2014).

The paper proceeds in five sections. In the next section, we provide some key summary statistics of the persistence and dispersion of regional labor market conditions over time. In Section III, we revisit the panel VAR framework proposed by BK to update the estimation results and discuss in detail the identification strategy in Section IV. In Section V, we document the pattern of regional adjustment mechanism in the recent decades, focusing particularly on shifts at the cyclical frequency and discuss some underlying mechanisms. Concluding remarks on macroeconomic implications of our findings are given in Section VI.

\section{Statistical Properties of Regional Employment}

An important stylized fact from the BK paper is that U.S. states have been experiencing very different growth rates in employment, and that these different growth rates have been consistently sustained over decades from 1950-1990. To see if this observation still holds, we split our sample of state-level data and plot average annual employment growth between 1976 and 1993 against the average growth rate between 1994 and 2011 by state, as shown in Figure 1.

The first sub-sample largely overlaps with the second half of BK's sample, during which states showed strong employment growth persistence relative to the preceding decades in the postwar period. Looking at Figure 1, it is clear that the persistence of state-specific employment growth rates still holds two decades later. At the top, we have Nevada, Arizona and Utah continuing to grow faster than in the rest of the nation, while Florida and Alaska, traditionally among the top performers, and appear to slow relative to the national average. Towards the lower end, we have Michigan increasingly deteriorating, while North and South Dakota and the District of Columbia have been experiencing a relative surge in employment growth. The slope of the regression line is 0.5 and $\mathrm{R}$ squared is 0.7 , hence the explanatory power of past for future average employment growth remains largely the same as in the BK sample, although the correlation is somewhat weaker. ${ }^{2}$

\footnotetext{
${ }^{2}$ A very similar picture emerges when we plot the state unemployment rates over the same time periods.
} 
One observation to note is that over the two 18-year sub-samples, the average employment growth rate has become less dispersed across states. This is visible in Figures 1, where the vertical axis has a smaller range than the horizontal one and by looking at the sample standard deviation: it falls from $1 \%$ to $0.6 \%$ between the two sub-samples. That is, although the average labor market conditions display strong persistence over long time periods, this persistence has somewhat weakened over time and state fortunes have converged more toward each other. We can also directly plot the evolution of the cross-sectional dispersion of employment growth as in Figure 2. Indeed, there is clear downward trend in employment growth dispersion across states starting in the late 1970s. The secular decline in spatial dispersion has been discussed for example by Kaplan and Schulhofer-Wohl (2013), who argue that this decline in geographic dispersion explains to some extent the declining interstate migration rate that occurred during the same time. Interestingly, the downward trend is interrupted by spikes of high dispersion during periods of recessions. Geographic specialization obviously plays a role for these spikes: as some industries (e.g. construction and auto industries) are more cyclical, that is, sensitive to aggregate shocks than others, a recession hits regions specializing in these cyclical industries (e.g. Michigan and Nevada) harder, increasing the dispersion of employment across regions. But even absent geographic specialization, if prior to a recession, most regions have relatively low unemployment, and at the onset of the recession unemployment increases in some states but not in others, dispersion will increase; see Fogli and others (2012).

For the remainder of the analysis, we will look at the joint behavior of state-level labor market variables that cover different labor market statuses. Suppose that each state produces a different bundle of goods, due to different industrial structure, and hence is subject to different shocks or responds differently to aggregate shocks. If a state is hit with a negative relative labor demand shock - that is, relative to the national average - the workers affected either become unemployed, drop out of the labor force, or migrate out of state. We investigate the magnitude and composition of this response by estimating a joint dynamic system in the three state-level variables: employment, unemployment rate, and labor participation rate. All labor market outcome variables are taken from various local and national datasets of the Bureau of Labor Statistics (BLS). In particular, state employment and unemployment data are taken from the Local Area Unemployment Statistics (LAUS) dataset from the BLS, which is in part based on CPS survey data. Table 1 reports key summary statistics of these state-level data across time and states as well as their detailed sources.

For comparability of results, we follow BK in terms of variable specification and estimation method in this section. The state-relative variables are defined in log deviation from their national aggregates. That is, for employment, es is the log employment in state $s$ minus $\log$ employment in the U.S. Consistent with BK, we find that state-relative employment levels are non-stationary as the hypothesis of a unit root cannot be rejected in the majority of the states as well as using panel unit root tests. We therefore use the first difference $\Delta e_{s}$ which corresponds to state-relative employment growth. Unlike the relative employment level, the relative employment/unemployment and participation rates do not exhibit the same persistence and tend to revert to long-term averages. The Impesaran-Shin panel unit root test, allowing for 4 lags, a state-specific constant and a time trend can reject the hypothesis of a unit root for the relative log employment rate (the negative of the relative log unemployment rate) le and relative log participation rate $l p$ at the 5 and 10 percent level of significance respectively. 
Overall, we can summarize that the employment growth and unemployment rates across states show strong, albeit weakening, persistence. Moreover, this persistence is related to the persistence of the mean of the employment growth and unemployment rates as opposed to persistent deviations from the means, as the stochastic behavior of both variables displays strong mean-reversion, a feature already documented by BK. Moreover, a new trend to note is the reduced dispersion of state-level labor market conditions over the last 20 years, with spikes of sharply rising dispersion during each aggregate downturn, an issue we will pick up in Section V.

\section{BASELINE ECONOMETRIC APPROACH AND RESUltS}

Given the time series properties above, we estimate a system of panel VAR equations as follows:

$$
\begin{aligned}
& \Delta e_{s t}=\alpha_{s 10}+\alpha_{11}(L) \Delta e_{s, t-1}+\alpha_{12}(L) l e_{s, t-1}+\alpha_{13}(L) l p_{s, t-1}+\varepsilon_{s e t} \\
& l e_{s t}=\alpha_{s 20}+\alpha_{21}(L) \Delta e_{s, t}+\alpha_{22}(L) l e_{s, t-1}+\alpha_{23}(L) l p_{s, t-1}+, \varepsilon_{s u t}, \\
& l p_{s t}=\alpha_{s 30}+\alpha_{31}(L) \Delta e_{s, t}+\alpha_{32}(L) l e_{s, t-1}+\alpha_{33}(L) l p_{s, t-1}+\varepsilon_{s u t} .
\end{aligned}
$$

We pool all states while allowing for state-specific constants, thus estimating the dynamics of the average state. We include two lags for each variable, following BK, and to keep sufficient degrees of freedom for estimation with shorter sub-samples, though extending up to four lags does not change the estimates substantially. This identification strategy assumes that current unexpected changes to state-relative employment growth within the year primarily reflect movements in regional labor demand. This assumption allows us to estimate the dynamic effects of a 1 percent shock to labor demand in a typical state on its relative unemployment rate, labor participation rate, and as a residual, the net-migration rate from other states. This is because in any period, we can decompose the change in the relative log employment level de (where $d$ denotes the change relative to pre-shock baseline) into:

$$
d e=d l e+d l p+m,
$$

where $m$ stands for the implied change in state-relative $\log$ working-age population $d \ln P$, i.e. the net migration rate following the shock.

There are several ways to estimate the equation system (1). Given the identification assumption that current shocks to employment growth are driven by labor demand only, $\Delta e_{s, t}$ is weakly exogenous in the equations for $l e$ and $l p$ and the system can be consistently estimated by OLS equation-by-equation, which is the estimation we use. The results are identical to transforming the system to a reduced form VAR and ordering employment growth first. Finally, we also use panel GMM to estimate the system to control for potential inconsistency of the fixed effects in the presence of lagged dependent variable. Given the long time series, the difference in estimation results is marginal (results not shown but available). The impulse responses estimated using OLS for the whole sample to a negative 1 percent shock to relative labor demand are plotted in Figure 3, with standard errors computed using Monte Carlo simulations with 500 replications. 
In the first year, a negative 1 percent shock to labor demand raises the state-relative unemployment rate by 0.22 percentage points and lowers the participation rate by 0.24 percentage points, with the effect peaking at 0.29 and -0.34 percentage points after 2 years respectively. The effect on the relative employment level peaks after four years at -1.73 percent, before decreasing gradually to a long-run value of around -1.2 percent. Hence over the long run, an initial shock of 1 percent leads to a permanent loss of 1.2 percent in the employment level, while employment growth, as well as unemployment and participation rates revert to the preshock average eventually. That is, interstate migration following the regional shock drives permanent changes in relative employment levels. It is also instructive to translate the changes from rates to number of workers. Of every 10 workers that lose employment, 2 workers become unemployed, 2 drop out of the labor force, and 6 workers migrate out of state within the first year following the shock. Compared to the BK results, the role of the participation margin increased (from 5 to 20\%), that of unemployment decreased (from 30 to 20\%) while net outmigration accounted for roughly the same 60 percent of the shock within the first year.

\section{Endogeneity OF STATE LAbor DEMAND SHOCKS}

\section{A. Test of OLS Identification Assumption}

Before moving on the analyze the evolution over time of regional adjustment, which is the main goal of this paper, we step back to test the identification assumption of BK that was used for the OLS estimation above, as well as by many other studies of labor mobility (see e.g. Decressin and Fatas, 1995; Jimeno and Bentolila, 1998). The crucial assumption is that unexpected shocks to relative employment growth $\varepsilon_{\text {set }}$ in the first equation of the system in 1 are purely state-relative labor demand shocks. This is equivalent to assuming that the contemporaneous employment growth $\Delta e_{s, t}$ is (weakly) exogenous in the second and third equation of the system 1 . To test this assumption, we consider two instrumental variables (IVs). The first IV is the so-called industry shift or industry mix variable, first proposed by Bartik (1991) and subsequently used extensively in the urban/regional economics literature: It measures the predicted employment growth in each state based on the state's industrial composition of employment and the nation-wide employment growth of each industry. That is, the instrument imix $_{s, t}$ is defined as:

$$
\operatorname{imix}_{s, t}=\Sigma_{\mathrm{j}=1}^{\mathrm{J}} \bar{\theta}_{s j t} \Delta \ln \left(\overline{\mathrm{e}}_{j t}\right) \text {, }
$$

where the state-specific industry share of employment $\bar{\theta}_{s j t}$ is taken as a 5-year moving average to avoid endogeneity with respect to current regional labor market conditions. The state-level industry employment shares as well as the national employment growth rates $\left(\Delta \ln \left(\overline{\mathrm{e}}_{j t}\right)\right.$ are taken from the Bureau of Economic Analysis (BEA) Regional Economic Ac- counts (Table SA25). The industries $j$ are based on 20 2-digit code SIC industries up until 2000, and 20 2-digit code NAICS industries starting in 2001, both cover full and part-time jobs in the entire non-farm private sector. The identification relies on the plausible assumption that an industry's national growth rate is uncorrelated with state-specific labor supply shocks.

Table 2 provides a snapshot of the latest distribution (in 2012) of employment across the different industries, as well as the variation in each industry's employment share across states. Overall, the highest employment share (more than 25 percent combined) is taken up by retail 
trade and health care/social services, while manufacturing industries provide only 8.4 percent of jobs. The spatially most concentrated industry is mining, which accounts for sizable employment shares in the traditional oil and coal states (e.g. Wyoming, Oklahoma, West Virginia), emerging as a major sector in North Dakota, while remaining almost insignificant in other states.

Regarding the employment composition across states, the District of Columbia and Nevada have among the most concentrated job mixes: the District has the highest concentration of high-paid (professional, educational) services and the lowest share in construction and manufacturing compared with the rest of the country, while Nevada provides the highest share of jobs in accommodation/food services and the lowest in educational and health services. This rich heterogeneity both across industries and space in employment distribution allows the industrymix IV to pick up substantial variation.

Figure 4 shows a histogram for the distribution of the predicted employment growth based on industry mix for the two sub-periods of the sample, 1976-1994 and 1995-2012. Across the two sub-samples, the mean and standard deviation of the distribution did not change significantly; however, the higher kurtosis as well as the longer tails of the distribution in the first half indicate more outliers in state-specific demand conditions in the earlier years, mostly driven by the mining boom and busts of the 70's and 80's (e.g. West Virginia, Wyoming), as well as the large hit experienced by states specialized in heavy industries and textile manufacturing during the recession of 1980 (e.g. Indiana, South Carolina). As regions increasingly diversified their production base and the Great Moderation continued, state fortunes have experienced less divergence, but still exhibited substantial variation in underlying industry composition, rendering the predicted employment growth variable a good instrument for state labor demand. Figure 5 illustrates the prediction power of the industry mix instrument for statelevel employment. The first stage regression using the full sample shows that a 1 percent increase in industry mix predicted employment growth corresponds to 1.2 percent increase in actual employment growth (both relative to national average), with the coefficient estimate being highly statistically significant. Splitting the sample into before and after the onset of the Great Recession, it is evident that booming states which grew stronger than predicted by their fundamentals before the crisis (Nevada, Florida, Arizona, New Mexico) were also those that experienced a larger hit than predicted during the crisis and its aftermath, reflecting largely the housing boom-bust cycles. On the other hand, the relative fortunes of North Dakota and the District of Columbia turned around from being laggards to booming regions, each due to statespecific development (energy and public sector).

The second IV we consider picks up exogenous changes to state-level labor demand in oil and gas extraction industries triggered by changes to the aggregate oil price. That is, we have:

$$
o i l_{s, t}=\bar{\theta}_{s t}^{o \& g} \Delta \ln \left(\frac{P \overline{o i l}}{P \overline{P I}}\right) t,
$$

where for each state, the aggregate relative price of oil (crude oil relative to national PPI) is interacted with the state-specific employment share in oil and gas extraction industries $\bar{\theta}_{\text {st }}^{\text {o\&g }}$ (computed in 5-year moving average). While the first IV measures state-level labor demand based on state-specific overall industrial composition and aggregate sectoral employment growth, the second IV picks up state-level labor demand variation driven by one particular sector (oil and gas) which plays a very important role in some states and less in others, hence the 
heterogeneity over time and space. ${ }^{3}$

Using imix $_{s t}$ and oil $_{s, t}$ to instrument for $\Delta \ln e_{s, t}$ in the equations for employment rate le and participation rate $l p$, we obtain the 2 SLS results summarized in Tables 3 and 4 respectively.

In each table, we first present the OLS results underlying the IRF in Figure 3. The second and third column in each table shows the 2SLS using each of the two IVs, while the last column shows the 2SLS result using both IVs. Let us first look at the employment rate regressions. First of all, both IVs show strong positive correlation with contemporaneous employment growth, with the industry mix variable being the stronger of the two as it picks up more variation across different industries (reflected in larger 1st stage coefficient and higher F statistics). In fact, when both IVs are used, the second stage estimate is close to the one with only imix as the IV, due to the much stronger first stage coefficient on imix compared to oil. Second, the second stage results, no matter using which IV, reveal a much stronger response of the state-relative employment (or unemployment) rate to state-specific labor demand shocks than do OLS results: a 1 percent negative employment shock from labor demand reduces the employment rate by 0.65 (or 0.44 using the oil IV) instead of 0.24 percent as with OLS. The Hausman test therefore clearly suggests a rejection of the exogeneity assumption in the OLS regression used by BK.

Results for the participation rate equation in Table 4 using the industry mix variable (either as the only IV or with together with the oil IV) also lead to rejection of the OLS identification assumption. The response of state-relative participation rate is in fact smaller using the IV compared with OLS: a 1 percent negative employment shock reduces the participation rate by 0.15 to 0.18 percent instead of 0.39 percent with OLS. The second stage estimate is close to the OLS result when the oil IV is used alone to identify state- specific labor demand shock. However, the oil IV turns out to be only a weak instrument as it reduces the first stage F statistics when added to the industry mix 2SLS regression (also the case in the employment rate equation) and hence is likely to have a larger bias towards the OLS estimate. Our application is an example of the so-called treatment effect/parameter heterogeneity discussed in Angrist and Imbens (1995). There are many reasons to expect that states with different industrial composition respond differently to sector-specific shocks. In particular, the oil price shock only picks up labor demand changes in oil-producing states, a subpopulation that is bound to behave differently than states with no relevant oil and gas industry employment, even if hit with a labor demand shock of the same size. Hence this heterogeneity among states in response to different instruments leads to different estimates in the second stage, each specific to the subpopulation (i.e. set of states) that respond to the instrument's "treatment". ${ }^{4}$ As the industry mix variable affects a larger set of states than the oil IV and is shown to be the dominant source of variation in the multiple IV regression, we choose it to be the preferred IV for the identification of state-

\footnotetext{
${ }^{3}$ Variants of this IV have also been used in e.g. Saks and Wozniak (2011) and Gallin (2004).

${ }^{4}$ This treatment effect heterogeneity also renders the usual test for over-identifying restrictions uninformative as it becomes rather a test of treatment effect homogeneity.
} 
specific labor demand shocks from now on. ${ }^{5}$

To trace the joint dynamic response of each labor market variable to a regional labor demand shock using the industry mix variable, we estimate the following reduced-form VAR system with imix being an exogenous forcing variable:

$$
\begin{aligned}
\Delta e_{s t} & =\alpha_{s 10}+\alpha_{11}(L) \operatorname{imix}_{s, t}+\beta_{11}(L) \Delta e_{s, t-1}+\beta_{12}(L) l e_{s, t-1}+\beta_{13}(L) l p_{s, t-1}+\varepsilon_{s e t}, \\
l e_{s t} & =\beta_{s 20}+\alpha_{21}(L) \text { imix }_{s, t}+\beta_{21}(L) \Delta e_{s, t-1}+\beta_{22}(L) l e_{s, t-1}+\beta_{23}(L) l p_{s, t-1}+\varepsilon_{s u t}, \\
l p_{s t} & =\beta_{s 30}+\alpha_{31}(L) \operatorname{imix}_{s, t}+\beta_{31}(L) \Delta e_{s, t-1}+\beta_{32}(L) l e_{s, t-1}+\beta_{33}(L) l p_{s, t-1}+\varepsilon_{s p t}
\end{aligned}
$$

To illustrate the difference between the OLS and the reduced-form IV estimates for the regional adjustment mechanism, in Figure 6, we plot the response of the each labor market variable, including net migration, to a 1 percent labor demand shock. As already implied by the parameter estimates in Table 3, the response of the state-relative unemployment rate to a given $1 \%$ labor demand shock is much stronger using the reduced-form identification in the first two years following the shock, whereas the participation rate responds less at all horizons. The net migration response is also substantially weaker than under OLS within the first year: a 1\% labor demand shock reduces the working-age population by $0.1 \%$ instead of $0.4 \%$ through net migration. While the migration response after 2 to 5 years is broadly similar across the two estimations, the long-term adjustment through net migration is by a third weaker, leading to a smaller total employment level change under reduced-form (around $0.8 \%$ instead of $1.2 \%$ ). It is also instructive to look at the decomposition chart in Figure 7 corresponding to the impulse response results. The decomposition of a 1 worker negative labor demand shock to changes in the pool of unemployed, non-participating, and net migrating workers gives an overview of the proportion of adjustment margins, particularly in the short-term. The estimated decomposition using OLS is compared against that obtained under reduced-form using the preferred imix IV as well as the oil IV as described above. The main difference is that the share of workers joining the pool of unemployed is much larger under the reduced-form estimation: between 46 and 75\% compared to $19 \%$ of the workers losing employment join the unemployment pool within the first year and between 60 and $80 \%$ instead of $22 \%$ within 2 years of the shock. Consequently, the share of workers leaving the state upon a negative employment shock is much smaller under reduced-form: only $13 \%$ or $30 \%$, depending on the IV, instead of $61 \%$ of the working-age population leave the state within the first year. Overall, the difference in results between OLS and reduced-form estimates are most pronounced in the short-run (within 1 to 3 years of the shock).

Overall, the IV identification reveals a lower degree of inter-state worker mobility in

\footnotetext{
${ }^{5}$ We have also tried adding a third instrument: the relative oil price change interacted with the intensity of oil usage in state-specific production, measured by petroleum use in barrels per chained 2005 Dollar of real GDP (data from the Energy Information Administration: www.eia.gov/states/seds/). The first stage is as expected negative but conditional on the industry mix IV, this third IV does not add any additional variation/information to the estimation and results are almost identical to those using imix alone, most probably because imix already incorporates variation in industries' sensitivity to oil price changes.
} 
response to state-relative labor demand shocks and in turn, a larger response of state-relative unemployment rates in the short run, reflected in smaller share of net-migration and larger share of unemployment flows conditional on a given size of labor demand shock. In the long-run, the total magnitude of inter-state migration which pins down the change in state-relative employment level is lower than previously identified through OLS estimations.

\section{B. Validation of Results with Migration and Population Data}

So far, the measured inter-state migration was backed out from the response of the employment and participation rates (as they jointly pin down the change in working-age population). It would be interesting to compare this derived response with one that is estimated using migration data directly. This is what we do in the following, using three different sets of inter-state migration and population data.

The first migration dataset we use is the annual State Population Estimates and Demographic Components of Change data from the U.S. Census Bureau's Population Estimates Program. The annual population estimates start with the decennial census data as bench- marks and add annual population component of change data, that is births, deaths, internal migration, immigration, emigration, and Federal (armed forces and civilian) movements, which derive from various governmental administrative records (national and local) and census distributions. ${ }^{6}$ In particular, state-level net domestic migration, our variable of interest, is derived by computing the net migration rate implied by the share of tax filers and dependents (equal exemptions) who changed addresses between any two tax filings based on IRS supplied Federal tax returns for the population 64 years and younger, and the implied net migration rate from the Medicare enrollment data for the population 65 years and older. This methodology to account for domestic migration (and separately, for international migration) was only introduced for the post-1990 population estimates, with the previous years' estimates only accounting for births and deaths and other components of change lumped into one residual. The available sample of state-level domestic net migration data therefore starts in 1991.

We estimate the following equation using the interstate migration data:

$$
m_{s t}=\alpha_{\mathrm{s}}+\gamma_{t}+\beta(L) m_{s, t-1}+\gamma(L) i m i x_{s, t}+\varepsilon_{s t}
$$

where $m s t$ is the state migration rate, i.e. total domestic net migration as a share of initial state population, detrended by a state-specific linear trend. The labor demand shock is identified by the same method using the contemporaneous change in employment predicted by a state's industrial composition imix. Furthermore, two lags of the dependent variable and the exogenous variable are allowed to be consistent with the VAR specification. The estimating equation is left parsimonious to infer the unrestricted response of migration to the labor demand shock. However, results are little changed if other lagged dependent variable of the VAR system (5) are also included as right hand side variables in 6 . To compare the backed-out migration response using the VAR with those using migration data directly, we simulate the cumulative response of net migration implied by the estimated equation 6 , with the cumulative response of the working-

\footnotetext{
${ }^{6}$ See detailed description in the U.S. Census Bureau, Statistical Abstract of the United States: 2000.
} 
age population from (5) following a shock to imix of the same size (in this case, 1.13 percent, which leads to 1 percent increase in contemporaneous relative employment growth). To make the same comparison for the OLS identification, we estimate equation 6 with labor demand identified by unexpected relative employment growth $\Delta e s t$ instead of imix, and compare the simulated response with the one backed out from the OLS system in (1). That is, we estimate:

$$
m_{s t}=\alpha_{s}+\gamma_{t}+\beta(L) m_{s, t-1}+\gamma(L) \Delta e_{s, t}+\delta_{1}(L) l e_{s, t-1}+\delta_{2}(L) l p_{s, t-1}+\varepsilon_{s, t},
$$

In this case, we also include the other lagged endogenous variables on the left hand side of the VAR system (1), so that a contemporaneous change to $\Delta e_{s, t}$ is the same unexpected innovation as the one captured in the VAR. Also, the paths of $\Delta e_{s t}, l e_{s t}$ and $l p_{s t}$ are calibrated to exactly match the VAR-implied IRF paths. Note that for this validation exercise, we re-estimate the VAR systems (1) and (5) using the same sample period as that available for equation 6 and 7, namely 1991-2012.

The second dataset we use is the state-level civilian noninstitutional population (16 years and older), also taken from the LAUS dataset of the BLS, which exists from 1976. We estimate the same equations 6, 7 using population growth instead of net migration rates and cumulate the changes to get the total response of working-age population to a labor demand shock. Figure 8 plots the implied response of state-level population to a 1 percent labor demand shock from the VAR and direct estimation using net migration (upper panel) and population data (lower panel).

Comparing the left two charts to the right ones, we can clearly see that the identification of state-relative labor demand shocks using imix leads to a much closer result between the VAR model and the data directly, particularly in the short and medium run. In the case using migration data, the response is somewhat larger than the model-implied one in the longer run. This is not surprising as the Census bureau's migration data covers net migration of all ages instead of just 16 years and older as used in the definition of employment and participation rates. Therefore, subject to the same shock, if over time, children and teenagers also respond to labor demand shocks (by following their families), this of course would lead to a larger overall population change. In the case using LAUS working-age population data, the data and modelimplied responses are very close to each other using the IV identification. The right hand side charts using the OLS identification show instead a large discrepancy between the data and VARimplied responses of state population to the same labor demand shock

We do one last check of the VAR-implied and directly estimated migration response by using the American Community Survey (ACS) data, which is a nation-wide survey that started in 2005 to collect similar information as the decennial census, but at an annual frequency. ${ }^{7}$ The advantage of this data is that we can construct annual net migration rates by age groups (as it is based on annual individual and household surveys instead of estimated as in the intercensal Population Estimates), and hence explicitly look at working- age migration rates. The big disadvantage is that net migration rates are only available starting in 2007 , hence not allowing us to estimate dynamic paths of adjustment as we did using longer time series of migration and

\footnotetext{
${ }^{7}$ Information from the survey generates data that help determine how federal and state funds are distributed each year, see U.S. Census Bureau (2009).
} 
population data above. We therefore only look at the short-term response of migration to labor market shocks, i.e. maximum 2 years after the shock.

To validate the identification strategy using imix, we first estimate a similar equation as 6 using the ACS (working-age) migration rates by state, but without lagged dependent variable as the 5 year sample is too short to alleviate concerns about fixed effect bias. To account for the dynamics of the dependent variable, we also estimate the equation by GLS by allowing for first order autocorrelation in the residual in addition to OLS. Due to the short sample, we only include the current value of imix and its first lag; extending up to 2 lags would not change the results but reduces efficiency. Similarly, to validate the OLS identification, we also estimate a similar equation as 6 , but with current and lagged employment growth instead of imix, as well as lagged employment and participation rates. The results are summarized in Table 5.

Although both identifications give a positive statistically significant response of working- age population migration to a state-relative labor demand shock within 2 years, only the estimation using imix for labor demand leads to a cumulative change that is not statistically different from the one obtained under the VAR (which is 0.494 percent after 2 years), with most of the response occurring with a 1 year lag. Using the OLS identification, the response is much smaller, occurring mostly in the current year, and the equality with the VAR implied response of 0.651 can be strongly rejected. ${ }^{8}$

The validation exercise using different datasets provides supporting evidence for the identification strategy adopted in the VAR system with the imix variable in 5. By the same token, it also confirms that at least in the short-run, state-level shocks are absorbed to a larger extent by state-level unemployment instead of interstate migration compared to the original result in $\mathrm{BK}$.

\section{The Evolution of Regional Adjustment}

\section{A. Documenting Patterns of Regional Adjustment}

One major purpose of the paper is to document whether patterns and channels of regional adjustments change over time. Having outlined an estimation framework that is supported by different datasets, we now embark on measuring the dynamic evolution of the estimates over time. Given the same regional shock, how has the propensity to migrate, become unemployed, or drop out of the labor force changed over the last 35 years? We are particularly interested in the evolution of interstate mobility as an adjustment mechanism over the last few decades. The migration literature has long documented a decline in interstate migration rates starting in the 1980s, but does this decline also imply a reduced sensitivity of migration to shocks? Figure 9 plots the implied migration response to a given 1 percent shock to state-level employment growth as derived earlier, but for three different samples: the BK sample of 1976-1990, the longer sample until before the crisis 1976-2007, and the full sample 1976-2012 which includes

\footnotetext{
${ }^{8}$ These VAR implied responses are computed based on estimates over 1990-2011, hence a longer sample than the ACS data coverage. The consistency between ACS estimated and VAR implied migration responses rely on the stability of migration response over the 1990-2011 period, an issue we will take up in the following section.
} 
the crisis years. We use overlapping samples to maximize the time-series dimension necessary to have reliable VAR estimates. This presentation of the data suggests that migration sensitivity to regional shocks, both in the short and long-run, has been decreasing since the 1990s, up until the Great Recession. Interestingly, this directional mobility appears to have in- creased during the crisis, moving the black line closer to the blue line.

Simply dividing the sample into sub-samples that each span more than a decade inevitably masks potentially important variation, and in particular, cannot account for changes in short-run adjustment at business cycle frequency. Before moving on to a more systematic analysis of annual variation in directional migration, we zoom in on two years, one before and one during the Great Recession, to see if the increased mobility during the crisis is born out by some simple cross-sectional correlation. In particular, we compare migration sensitivity by plotting simple scatter plots of state-level net-migration rates against state-level lagged predicted employment growth (as the response is strongest at 1 year after the shock according to the VAR). The net-migration rate is taken as deviation from state-specific linear trend to account for state-specific migration evolutions (due to e.g. amenities, industry agglomeration) as well as aggregate mobility trends (in particular the secular overall decline in migration documented in the literature). The resulting correlation plots before and during the Great Recession (2007 vs. 2009 ) is presented in Figure 10. We find that the stronger migration response is indeed also reflected in these simple correlation plots: higher employment growth as predicted by a state's industry mix is associated with stronger net in-migration (relative to trend), and this positive relation is stronger at the height of the recession than during the year before its onset.

In the next step, we choose the following estimation strategy to systematically track changes from year to year. We implement a series of expanding window regressions: First, we estimate the VAR system in (5) from 1976 to 1990 (the BK sample). We then expand the sample by adding one year at a time and re-estimate the VAR. The difference in estimates between any consecutive expanding windows reflects how the last year of observation changes the estimated average dynamics. This allows us to construct annual changes between 1990 and 2012 to any statistics of interest. ${ }^{9}$ After estimating a VAR system for each sub-sample, we calculate the implied propensity to migrate, become unemployed or drop out of the labor force given a labor demand shock of 1 worker. To enhance representativeness and avoid that the estimation be overly influenced by small states with big shocks in the marginal year, we weight the observations by state-level population (averaged over the sample period). The implied evolution of migration sensitivity in the same year and 1 year after the shock is plotted in Figure $11^{10}$

Looking at the evolution of migration response, two features stand out: First, at least since 1990, there has been a decline in migration response to state-relative demand shocks which largely stabilized in the late 1990s. Between 1990 and 2005, responding to say a negative state shock of 1 worker, the average share of workers leaving the state in the same year decreased from 0.1 to 0.02 , and from 0.56 to 0.46 cumulatively after 1 year. Second, the cyclical sensitivity

\footnotetext{
${ }^{9}$ These methods have been widely used in the finance literature, in particular for forecasting purposes. See e.g. Pesaran and Timmerman (2002).

${ }^{10}$ The un-weighted series delivers largely the same result, but is somewhat more volatile.
} 
of migration increased greatly during the Great Recession. Including the crisis years in the expanding window regression brings the average 1st year response back to the level before 1990. ${ }^{11}$ These two observations are consistent with the long-run migration response derived from sub-sample VAR in Figure 9.

Of course, changes in migration response have to be compensated by other margins of adjustment. The mirror image to a decreasing migration response was an increasing unemployment response from 1990 until the onset of the crisis while the participation response has been largely stable until the early 2000. As migration sensitivity surged during and immediately after the Great Recession, we observe at the same time less sensitivity of regional unemployment and participation in response to relative shocks. The declining trend in participation adjustment since the early 2000 is consistent with a declining overall aggregate labor force participation rate in the U.S. due to aging demographics and hence less mobility into and out of the labor force as older workers' participation rate is less cyclical (see Balakrishnan and others, 2014). It may also be related to the declining share of marginally attached persons in the non-participation pool and thus less cyclical transition from non-participation as documented by Barnichon and Figura (2013).

Next, to further validate our findings from expanding window regressions, we would like to know if the cyclical pattern of mobility is also reflected in other data sources. We do so by looking at micro data from the Current Population Survey (CPS). Using the March Supplement which contains information on the respondent's state of residence 1 year ago, we can compute the probability to migrate out of state for different population groups. Figure 13 shows the annual interstate migration rate for working-age adults for the past three decades, largely the same sample we used to estimate the VAR above. As has been documented widely in the literature, interstate mobility has been steadily declining with- out any cyclical pattern. ${ }^{12}$ However, the counter-cyclical pattern we uncovered above applies to the migration conditional on a relative shock to the state labor market, and not the overall (unconditional) migration rate as plotted in Figure 13. To present a proxy for this conditional migration response, we utilize respondents' stated reason for moving, which has been included in the March supplement of the CPS starting in 1999. Specifically, we compute the share of working-age labor force that moved across state borders to "look for work or lost job". An advantage of this particular variable is that it also implicitly gives us information on the labor market status of the respondent at the time of the move: a person that moved to "look for work or lost job" was most likely either a labor market entrant or unemployed at the time of the move, and hence was either out of the labor force or unemployed (in other words non-employed) for at least part of the reference year. ${ }^{13}$ As

\footnotetext{
${ }^{11}$ In fact, migration response already picks up in 2006 and 2007 before the Great Recession. This increase is most likely driven by the aftermath of Hurricane Katrina, which triggered one of largest diaspora within the United States in modern times.

${ }^{12}$ Wherever we refer to migration rates from the CPS, we exclude data from survey respondents whose migration answers have been imputed starting in 1996 to avoid the upward bias documented in Kaplan and Schulhofer-Wohl (2012).

${ }^{13}$ Note that this migration category is different from the job to job migration of the employed, which is covered by the reason "new job or job transfer".
} 
the migration decision for job-search should respond more strongly to variation in regional economic conditions than migration for other reasons (family, retirement, college etc.) in the overall adult population, we would expect it to qualitatively follow the pattern derived from the $\mathrm{VAR}$, if that pattern correctly reflects the underlying dynamics.

Figure 14 presents the evolution of the job-search-related migration rate. In spite of the limited number of years, the series does exhibit the highest mobility rate during the last two recessions. As the reason for migration has only been surveyed starting in 1999, we cannot tell whether the decline after the 2001 recession is due to a long-term trend or cyclical forces. Nevertheless, we can clearly observe that the job-search related migration rate increased noticeably following the Great Recession. The share of working-age population that moved to another state in search of job opportunity started increasing at the onset of the recession, and surged by more than half between 2007 and 2008 (or more precisely, March 2007 to March 2009). The small magnitudes of computed job-search migration rates in Figures 14 (less than 1 percent) may give the impression of little economic significance. However, unlike the VARderived responses conditional on a shock of given magnitude, these migration rates are averages across all states, regardless of the underlying regional shock. The severity of the crisis was been very heterogeneous across U.S. states, as some states, particularly those experiencing a housing bust (e.g. Nevada), were hit very hard, while others came out relatively unscathed or even experienced a boom (e.g. North Dakota). The average migration rate in each year therefore masks very large dispersion across states, even more so if cumulated over several years. Table 6 illustrates this point for the recession years. During the peak year 2008-2009, more than 1 percent of the labor force moved out of Nevada and West Virginia (reflecting varied cyclical but also structural weakness across states), and over three years 2007-2010, around 2 percent of the labor force moved away from Idaho and Nevada (where the unemployment rate increase was among the highest, by 6 percent and 9 percent respectively) explicitly to look for jobs in another state, while in Delaware, Kansas and North/South Dakota, virtually no job-search induced outmigration was registered by the CPS. Among the unemployed population of the labor force (i.e. those most "at risk" for job-search migration), the out-migration rate is in most cases much higher: almost 12 percent of unemployed moved out of Nevada in search of jobs, while still none was registered for Delaware, Kansas and the Dakotas.

To sum up, the reduced form VAR estimates imply a surge in mobility in response to regional shocks following the Great Recession. And this counter-cyclical pattern during the crisis is reflected in the evolution of job-search induced migration rates computed from micro data of the CPS. A breakdown by state reveals that indeed the severity of the downturn seems to be a determinant of mobility, with large dispersion in job-search migration rates registered among states with varying crisis experience. In the remainder of the paper, we focus on this new result first by formally testing for the counter-cyclical migration dynamics within the established VAR framework and second, by suggesting an explanation for this phenomenon.

\section{B. Regional Adjustment During Recessions and Expansions}

The evidence presented in Figures 11, as well as 14 both suggest that the cyclical response of migration typically increase during recessions. To test for this hypothesis, and following Auerbach and Gorodnichenko (2012), we modify the system of equation (5) as follows: 


$$
\begin{aligned}
x_{s t}= & \alpha_{s 10}+\alpha_{11}^{r} F\left(z_{t}\right)(L) \operatorname{imix}_{s, t}+\beta_{11}^{\mathrm{r}} F\left(z_{t}\right)(L) \Delta e_{s, t-1}+\beta_{12}^{r} F\left(z_{t}\right)(L) e_{s, t-1}+\beta_{13}^{\mathrm{r}} F\left(z_{t}\right)(L) l p_{s, t-1} \\
& +\alpha_{11}^{\mathrm{e}}\left(1-F\left(z_{t}\right)\right)(L) i m i x_{s, t}+\beta_{11}^{\mathrm{e}}\left(1-F\left(z_{t}\right)(L) \Delta \mathrm{e}_{s, t-1}\right. \\
& +\beta_{12}^{\mathrm{e}}\left(1-F\left(z_{t}\right)\right)(L) l e_{s, t-1}+\beta_{13}^{\mathrm{e}}\left(1-F\left(z_{t}\right)(L) \operatorname{lp}_{s, t-1}\right. \\
& +\varepsilon_{s x t}, F\left(\mathrm{z}_{\mathrm{t}}\right)=\frac{\exp \left(-\gamma z_{t}\right)}{1+\exp \left(-\gamma z_{t}\right)} \operatorname{Var}\left(z_{t}\right)=1, E\left(z_{t}\right)=0
\end{aligned}
$$

where $x$ stands for each of the three variables $\Delta e, l e$, and $l p$ as in the reduced form VAR system 5 and $F()$ is a transition function of the state of the economy $z$ (normalized so that $\gamma$ is scale invariant). A positive $z$ indicates an expansion, while a negative $z$ indicates a recession. We set $z$ equal to the three-years moving average of US output growth rate and we calibrate $\gamma=1.5$ so that economy spends about 20 percent of time in a recession regime (that is, $\operatorname{Pr}(F(z t)>0.8)=$ $0.2)$ where we define an economy to be in recession if $F(z t)>0.8$. The calibration is consistent with the duration of U.S. recessions according to NBER business cycle dates (Auerbach and Gorodnichenko, 2012). This modified system of three equations in is essentially an augmented version of equation system (5) where each coefficient is interacted with a measure of the state of the aggregate economy and hence allowed to vary continuously along the business cycle.

This approach is equivalent to the smooth transition autoregressive (STAR) model developed by Granger and Teravistra (1993). The main advantage of this approach relative to estimating SVARs for each regime is that it considers a larger number of observations to compute the impulse response functions, making thus the response more stable and precise.

Figure 15 presents the response of each labor market variable, including net migration, to a 1 percent labor demand shock during recessions $F(z t)=1$, expansions $F(z t)=0$. As point of comparison, we also include in the chart the baseline results (linear model) reported in the previous section. While the response of the unemployment rate is not significantly different across the two economic regimes, the response of participation rate is economically and statistically significantly lower during recessions than expansions. ${ }^{14}$ As a result, the cyclical response of net migration (computed as residual) is larger in recessions than in expansions both in the short and long run.

As a complementary approach to test whether the cyclical response of migration varies with the state of the economy, we look at working-age population data directly as done in Section V.B. In particular, we modify equation 6 as follows: ${ }^{15}$

$$
\begin{aligned}
m_{s t}=\alpha_{s}+\gamma_{t} & +\beta^{r} F\left(\mathrm{z}_{\mathrm{t}}\right)(\mathrm{L}) m_{s, t-1}+\gamma^{r} F\left(\mathrm{z}_{\mathrm{t}}\right)(L) i m i x_{s, t} \\
& +\beta^{e}\left(1-F\left(\mathrm{z}_{\mathrm{t}}\right)\right)(\mathrm{L}) m_{s, t-1}+\gamma^{e}\left(1-F\left(\mathrm{z}_{\mathrm{t}}\right)\right)(L) i m i x_{s, t}+\varepsilon_{s t},
\end{aligned}
$$

The results of this exercise, presented in Figure 16, confirm that the cyclical response of

\footnotetext{
${ }^{14}$ Walds Chi-square statistics of the differences of the responses are statistically significant at 5 percent.

${ }^{15}$ We use working-age population here instead of net migration to maximize the number of years to have sufficient expansions and recessions.
} 
population change or net migration is economically and statistically significantly higher in recessions than in expansions both in the short and in the long run. Indeed, a Wald's Chi-square test statistic of the differences of the responses is statistically significant at 5 percent both in the short and long run.

\section{What Drives the Pattern of Mobility?}

The new finding of our paper is that, while trending downward in normal times, interstate migration in response to regional disparities spikes up strongly during recessions. ${ }^{16}$ Reasons for the secular decline in overall migration in the U.S. is subject to active debate in the literature. For example, Kaplan and Schulhofer-Wohl (2013) show that the mix of jobs and occupation-specific incomes have become more and more similar across states in the past 20 years. Molloy and others (2014) attribute reduced average mobility to smaller benefits from jobto-job transitions. Ganong and Shoag (2013) relate much of the decline in income convergence and population flows to higher housing supply regulations. However, none of these stories can explain the cyclical pattern of migration, especially since this cyclical variation appears to be born out by the unemployed and labor market entrants. While our main focus is to document this new empirical stylized fact, we also explore two potential mechanisms for the migration cyclicality in the remainder of the paper.

\section{Compositional Effects}

We know that mobility is higher among the unemployed and labor market entrants than the rest of the population. ${ }^{17}$ At the same time, the share of unemployed and, to a lesser extent, inactive population also increases in downturns. Therefore, the surge in job-search mobility noted in Figure 14 during the Great Recession could be driven by either an in- crease in the share of the non-employed population in the labor force, or an increase in job-search mobility within this group, or both. Table 7 presents the job-search migration rate for the overall labor force, as well as by different employment statuses. Several observations are worth noting. First, on average, indeed the unemployed, particularly the long-term unemployed group in the labor force are more inclined the migrate to find work (5-6 times more likely than average). The second most mobile group are the labor market entrants, i.e. individuals who joined the labor force sometime during the previous reference year (partly NILF) or at the beginning of the current year (all year NILF), while job-search mobility is almost zero for the full-year employed population. Second, relative to the migration rate in the benchmark year before the crisis, job-search related migration rate increased within each of the groups of the labor force during the years of the Great Recession (2007-2010), with the sharpest increase observed among the long-term unemployed and labor market entrants, for whom job-search mobility almost tripled over the period.

\footnotetext{
${ }^{16}$ Our result is complementary to Saks and Wozniak (2011), who show that migration for reasons other than to arbitrage local demand shocks is in fact pro-cyclical. This may explain why the overall migration rate in Figure 13 is acyclical.

${ }^{17}$ The 1-year interstate migration rate for the unemployed has been 4.74 percent on average in 1976-2013, roughly double the 2.35 percent average interstate migration rate for the overall population.
} 
To disentangle the purely compositional effect of cyclical shifts within the labor force from the within-group changes on overall job-search migration, the last row of Table 7 computes the counterfactual job-search migration rate holding the within-group migration rate fixed at the benchmark value, and instead only allowing the population shares to change as observed in the data. We find that the compositional effect only accounts for less than 20 percent of the increase in job-search mobility in the peak year 2008-2009 while it potentially explains up to 75 percent of the change in subsequent years during early recovery (see also Figure 14). That is, in the initial years of the crisis, the bulk of the increase in interstate migration for job-search is driven by higher migration rates within the groups, particularly those unemployed at least a year and recent labor market entrants.

Finally, we also checked whether demographic characteristics of the unemployed and labor market entrants vary during downturns in a way that could drive the counter-cyclical mobility of these groups. Elsby and others (2013) have argued for example, that the composition of the unemployed along some observable characteristics explain the bulk of the cyclicality of the participation margin. While we do find, consistent with the literature (see e.g. Bound and Holzer, 2000), that mobility differs significantly among some major demographic groups, even within the group of the unemployed and labor market entrants: men are more mobile than women, prime-age individuals are more mobile than the old and very young, white individuals are more mobile than other racial groups, and most of all, higher-educated individuals (particularly those with college education) more mobile than less educated ones. ${ }^{18}$ However, changes in the composition of the unemployed and labor market entrants along these demographic characteristics during the Great Recession cannot explain any of the increase in their overall job-search mobility. In other words, the increase was caused by higher propensity to migrate for job-search among unemployed and new entrants within the demographic groups, with much of the change due to higher migration of college-educated young adults (20-25 years) among labor market entrants, while it was more evenly spread across educational and age groups among the unemployed.

\section{The Role of Risk Sharing}

Having ruled out composition effects as a cause for higher job-search migration during re- cessions, we now turn to another hypothesis. There are many reasons why the long-term unemployed may have higher incentives to leave a worse-performing state in search of better opportunity than the newly unemployed, as potential hysteresis effects make it more urgent for them to find a job. Similarly, labor market entrants are arguably more inclined than, say, recent job losers to move to better-performing regions to increase their chance at a quality first job (or a job in general), as their career path is persistently determined by the initial labor market outcome (see Oreopoulos and others, 2012). But it is not clear why their job-search mobility should be higher during recessions. After all, while a recession may exacerbate the employment prospect of a worse-performing state, the expected job-finding rate also goes down everywhere else. And benefits from migration other than to exploit spatial labor demand arbitrage have been shown to be lower in recessions, see Saks and Wozniak (2011).

\footnotetext{
${ }^{18}$ This demographic shift share analysis is available upon request.
} 
A possible explanation for why the response of migration varies with the state of the economy is that consumption risk sharing increases in booms and decreases during re- cessions (Hoffmann and Shcherbakova-Stewen, 2011). In other words, people may tend to move more when their ability to smooth idiosyncratic shocks decreases. To test for this hypothesis, we proceed in three steps: first, we test whether consumption risk sharing increases in booms and decreases during recessions; second, we analyze whether the response of migration varies with the degree of consumption risk sharing; and third we re-assess whether the response of migrations varies with the state of the economy once we control for the degree of consumption risk sharing.

For the first step, we run the following regression:

$$
\begin{aligned}
\Delta \mathrm{c}_{\mathrm{s}, \mathrm{t}}= & \left.\alpha+\gamma_{t}+\alpha^{\gamma} F\left(z_{t}\right)\right)(L) \Delta y_{\mathrm{s}, \mathrm{t}}+\alpha^{e}\left(1-F\left(z_{t}\right)\right)(L) \Delta y_{\mathrm{s}, \mathrm{t}} \\
& +\beta^{\mathrm{r}} F\left(z_{t}\right)(L) \Delta \mathrm{c}_{\mathrm{s}, \mathrm{t}-1}+\beta^{\mathrm{e}}\left(1-F\left(z_{t}\right)\right)(L) \Delta c_{\mathrm{s}, \mathrm{t}-1}+\varepsilon_{\mathrm{s}, \mathrm{t}},
\end{aligned}
$$

where $\Delta c$ is per-capita private consumption growth, $\Delta y$ is per-capita GDP growth, both varying at the state level and over time. If financial markets are complete, consumption growth should be independent of a state's income or GDP growth as households will borrow and save in a way to perfectly smooth their consumption path. Therefore, the coefficients $\alpha r$ and $\alpha e$ represent the degree of uninsured consumption shock during recessions and expansion, respectively, allowing the effect to occur with a lag of up to 2 years; and $F()$ is a transition function of the state of the economy $z$. Based on these estimates, Figure 17 presents the dynamic evolution of the degree of uninsured shocks in response to state specific GDP shock during recessions $F\left(z_{t}\right)=1$ and expansions $F\left(z_{t}\right)=0$. First, we see that the average estimate of the contemporaneous uninsured risk (i.e. the degree of income shock that is not smoothed in the year of the shock) is about 0.2 , consistent with the literature (Hoffmann and Sherbakova-Stewen, 2011). However, the lag structure turns out to be important: much of the effect of income shock on consumption occurs within 1-2 years after the shock, so that the cumulative degree of uninsured shock increases to 0.45 in the long run. That is, a 1 percent change in income leads, over time, to 0.45 percent change in consumption.

Even more important than the lag structure is the impact of the aggregate business cycle. Figure 17 shows that while the degree of uninsured shocks is particularly high during recessions, where the change in consumption is one to one with change in income, it is close to zero and not statistically significant during aggregate expansions. That is, during expansions, states that experience negative income shocks can, not instantly but by 2 years onward after the shock, dissave or borrow to smooth their consumption.

We then assess whether the response of migrations varies with the degree of consumption risk sharing, by estimating the following specifications:

$$
\begin{aligned}
m_{\mathrm{st}} & =\alpha_{s}+\gamma_{t}+\beta^{\mathrm{r}} F\left(v_{t}\right)(L) m_{\mathrm{s}, \mathrm{t}-1}+\gamma^{\mathrm{r}} F\left(v_{t}\right)(L) i m i x_{\mathrm{s}, \mathrm{t}} \\
& =\beta^{\mathrm{e}}\left(1-F\left(v_{t}\right)\right)(L) \mathrm{m}_{\mathrm{s}, \mathrm{t}-1}+\gamma^{\mathrm{e}}\left(1-F\left(v_{t}\right)\right)(L) \text { imix }_{\mathrm{s}, \mathrm{t}},
\end{aligned}
$$

where $F()$ is a transition function of the degree of uninsured shock $v_{t}$ estimated using crosssectional regression of per-capita state consumption growth and per-capita state output growth 
from 1970 to $2005 .^{19}$

$$
\Delta c_{s, t}=v_{t} \Delta y_{s, t}+\theta_{t}+\varepsilon_{s t}
$$

Estimates of $v_{t}$, typically lying between 0 and unity, can be interpreted as the timevarying degree of uninsured idiosyncratic output risk in the average state. ${ }^{20}$ The results presented in Figure 18 show that the response of migration varies with the degree of consumption risk sharing. In particular, the cyclical response of net migration is economically and statistically significantly higher, both in the short and in the long run, when consumption risk sharing is low and vice versa. Specifically, when consumption risk sharing is absent and $v=1$ (low shocksmoothing regime), the cumulative effect of a 1 percent negative labor demand shock is a population loss of more than 1 percent after 2-3 years, whereas there is no migration effect in response to the same shock if risk-sharing is complete and $v=1$. Indeed, a Wald's Chi-square test of the differences of the impact and long-run responses between the two risk-sharing regimes is statistically significant at 1 percent.

Finally, we re-assess whether the response of migration still varies with the state of the economy once we control for the degree of consumption risk-sharing. For this purpose we reestimate equation 9 adding as a control the interaction term involving the degree of uninsured risk $F\left(v_{t}\right)(L)$ imix $_{(s, t)}$. The result presented in Figure 18 (lower panel) shows that, once we control for the degree of uninsured shocks, the migration response during expansions and recessions are indistinguishable from each other. In other words, for a given degree of consumption smoothing, the cyclical response of migration is not significantly higher in recessions than in expansions. This, in turn, suggests that consumption risk sharing plays a key role in explaining the cyclical response of interstate migration during recessions and booms.

To sum up the results of this section, we documented using different estimation strategies (expanding window VAR, cyclical interaction VAR) and datasets (state-level population data, CPS micro data) that the response of migration to state-level labor market conditions is strongly counter-cyclical and that pattern is strongly correlated with the degree of consumption smoothing at state-level over the business cycle. We cannot conclude whether the variation in consumption smoothing is the cause for the pattern of migration, or whether it is driven by other forces that vary over the business cycle which, in turn, also affect migration decisions. However, the fact that the degree of risk sharing correlates so strongly with migration response suggests that the extent of consumption risk sharing at least acts as an important channel in determining mobility in the face of spatial disparities. Moreover, our results with micro data showing that it is mostly the long-term unemployed and labor market entrants that bear the bulk of increased

\footnotetext{
${ }^{19}$ State consumption data are taken from Zhou (2010). Although more recent consumption data are avail- able elsewhere through 2012, we decided to stop the estimation sample in 2005 as state consumption series exhibit large jumps between 2005 and 2006 suggesting a possible change in the methodology and inconsistency between the series.

${ }^{20}$ Sequences of such regressions have been previously used by Sorensen and others (2007) to study the impact of globalization on international risk-sharing, and by Hoffmann and Shcherbakova-Stewen (2011) to assess the cyclical properties of US interstate risk sharing.
} 
migration response further support the consumption smoothing hypothesis. The long-term unemployed tend to experience the largest and most persistent income losses as they run out of unemployment insurance benefits faster and face lower job-finding prospects than other groups. Labor market entrants have the least savings to tap into and less collateral to obtain loans. Therefore one would also expect these groups to have the lowest ability to smooth consumption over the downturn, see related evidence in Crossley and Low (2013).

By relating migration dynamics with consumption risk sharing, we connect with different strands of the literature that explain the secular and cyclical variation in risk sharing. Morgan and others (2004) show that banking regulation in the United States have had important implications for co-movement of state business cycles, with implication for interstate migration. More recently, Campbell and Cocco (2007) show, using UK micro data, that an important driver for regional consumption are regional house prices, representing a source of risk that is not shared across regions.

\section{Concluding Remarks}

The findings of our paper address some of the important questions about the efficiency of the US labor market. Our results address the question of mismatch in the US labor market and its implication for the recovery from the Great Recession. We show that, notwithstanding the negative secular trend, the response of inter-state migration to regional asymmetries in job opportunities actually increases in recessions. Therefore, geographic mismatch is not likely to play a role for the weak labor market recovery. This is consistent with findings in Sahin and others (2011) who also conclude, using micro data, that geographic mismatch plays no role for the rise in the unemployment rate during the crisis and its aftermath.

That said, our results leave open the question of whether the uncovered cyclical pat- tern in mobility is efficient and if policies can improve welfare by influencing individuals decision to migrate. Our new result on the link between consumption smoothing and mobility indicate that migration decisions are also determined by frictions in financial market and that welfare outcomes depend on interactions of complex forces. For example, Yagan (2014) shows that, in spite of sufficiently high directional migration during the Great Recession, migrants from worse to better performing states still suffer from lower job-finding prospects than locals. This implies that mobility is not sufficient to act as an insurance mechanism to spatial labor market disparities, and that other frictions besides limited mobility also play a role in preventing spatial arbitrage. Exploring how frictions and policies can interact in shaping dynamics of labor mobility remains an important area for future research. More generally, studying spatial patterns of labor market adjustments offers an alternative lens to understanding the workings of the aggregate labor market and the propagation of macroeconomic shocks. 


\section{REFERENCES}

Angrist, Joshua, D. and Guido Imbens, 1995, "Two-stage Least Squares Estimation of Average Causal Effects in Models with Variable Treatment Intensity," Journal of the American Statistical Association, Vol. 90, No. 430, (June) pp. 430-42.

Auerbach, Alan J., and Yuriy Gorodnichenko, 2012, "Measuring the Output Responses to Fiscal Policy," American Economic Journal: Economic Policy, Vol. 4, No. 2, (May) pp. 1-27.

Balakrishnan, Ravi, Mai Dao, Juan Sole, and Jeremy Zook, 2014, "Recent US Labor Force Participation Dynamics: Reversible or Not?” IMF Selected Issues Paper, (July) pp. 5-29 (Washington: International Monetary Fund).

Barnichon, Regis, and Andrew Figura, 2013, "Declining Labor Force Attachment and Downward Trends in Unemployment and Participation," Finance and Economics Discussion Series, Working Paper No. 2013-88, Federal Reserve Board.

Bartik, Timothy, J., 1991, "Who Benefits from State and Local Economic Development Policies?" (Kalamazoo, Michigan: W. E. Upjohn Institute for Employment Research).

Beyer, Robert, C., and Frank Smets, 2014, "Has Mobility Decreased? Reassessing Regional Labour Market Adjustments in Europe and the US," Economic Policy, forthcoming.

Blanchard, Olivier, and Lawrence F. Katz, 1992, "Regional Evolutions," Brookings Papers on Economic Activity 1, Vol. 3, pp. 1-77.

Bound, John and Harry J. Holzer, 2000, "Demand Shifts, Population Adjustments, and Labor Market Outcomes during the 1980s," Journal of Labor Economics, Vol. 18, No. 1 (January), pp. 20-54.

Campbell, John Y., and João F. Cocco, 2007, “How Do House Prices Affect Consumption?

Evidence from Micro Data," Journal of Monetary Economics, Vol. 54, No. 3, pp. 591-621.

Crossley, Thomas, F. and Hamish W. Low, 2013, "Job Loss, Credit Constraints and Consumption Growth," The Review of Economics and Statistics, forthcoming.

Decressin, Jörg and Antonio Fatas, 1995, "Regional Labor Market Dynamics in Europe," European Economic Review, Vol. 39 (December) pp. 1627-55.

Elsby, Michael, W.L., Bart Hobijn, and Aysegül Sahin, 2013, "On the Importance of the Participation Margin for Market Fluctuations," Federal Reserve Bank of San Francisco Working Paper, 2013-05.

Fogli, Alessandra, Enoch Hill, and Fabrizio Perri, 2012, "The Geography of the Great Recession," NBER Working Paper No. 18447.

Frey, William H., 2009, “The Great American Migration Slowdown: Regional and Metropolitan Dimensions," Metropolitan Policy Program, Brookings Institution (December). 
Gallin, Joshua, H., 2004, "Net Migration and State Labor Market Dynamics," Journal of Labor Economics, Vol. 22, No. 1 (January), pp. 1-21.

Ganong, Peter and Daniel Shoag, 2013, "Why has Regional Income Convergence in the US Declined?” HKS Working Paper No. RWP12-028. Working Paper.

Granger, Clive, W., and Timo Terasvirta, 1993, Modelling Nonlinear Economic Relationships, (New York: Oxford University Press).

Hoffmann, Mathias and Iryna Shcherbakova-Stewen, 2011, "Consumption Risk Sharing over the Business Cycle: The Role of Small Firms' Access to Credit Markets," The Review of Economics and Statistics, Vol. 93, No. 4, pp. 1403-16.

Jimeno, Juan, Samuel Bentolila, 1998, "Regional Unemployment Persistence (Spain, 19761994)," Labour Economics, Vol. 5, No. 1 (March), pp. 25-51.

Kaplan, Greg, Sam Schulhofer-Wohl, 2012, "Interstate Migration Has Fallen Less than You Think: Consequences of Hot Deck Imputation in the Current Population Survey," Demography, Springer, Vol. 49, No. 3 (August), pp. 1061-74.

— 2013, "Understanding the Long-run Decline in Interstate Migration," Federal Reserve Bank of Minneapolis Working Paper No. 697.

Kocherlakota, Narayana, 2010, “Inside the FOMC," President's Speech, Marquette, MI. August $17,2010$.

Molloy, Raven, Christopher L. Smith, and Abigail Wozniak, 2011, "Internal migration in the United States," Journal of Economic Perspectives, American Economic Association, Vol. 25, No. 3, pp. 173-196.

— 2014, "Declining Migration within the US: The Role of the Labor Market," NBER Working Paper No. 20065 (Cambridge, MA: National Bureau of Economic Research).

Morgan, Donald, Bertrand Rime, and Philip E. Strahan, 2004, "Bank Integration and State Business Cycles," The Quarterly Journal of Economics, Vol. 119, No. 4 (November), pp. $1555-84$.

Oreopoulos, Philip, Till von Wachter, and Andrew Heisz, 2012, "The Short- and Long-Term Career Effects of Graduating in a Recession," American Economic Journal: Applied Economics, Vol. 4, No. 1 (January), pp. 1-29.

Partridge, Mark, D. and Dan S. Rickman, 2003, "The Waxing and Waning of Regional Economies: The Chicken-Egg Question of Jobs Versus People," Journal of Urban Economics, Vol. 53, No. 1(January), pp. 76-97.

Pesaran, M. Hashem, and Allan Timmermann, 2002, "Market Timing and Return Prediction under Model Instability," Journal of Empirical Finance, Vol. 9, No. 5 (December), pp. $495-510$. 
Sahin, Aysegül, Joseph Song, Giorgio Topa, and Giovanni Violante, 2011, "Measuring Mismatch in the US Labor Market," Working Paper, November.

Saks, Raven and Abigail Wozniak., 2011, "Labor Reallocation over the Business Cycle: New Evidence from Internal Migration,” Journal of Labor Economics, Vol. 29, No. 4, pp. 697-739.

Sorensen, Bent E., Yi-Tsung Wu, Oved Yosha, and Yu Zhu, 2007, "Home Bias and International Risk Sharing: Twin Puzzles Separated at Birth," Journal of International Money and Finance, Vol. 26, No. 4 (June), pp. 587-605.

Yagan, Danny, 2014, "Moving to opportunity? Migratory insurance over the Great Recession," Working Paper, January.

Zhou, Xia, 2010, "Essays on US State-level Financial Wealth Data and Consumption Data," PhD dissertation, The Johns Hopkins University. 
Table 1. Summary Statistics of State-level Data

\begin{tabular}{|c|c|c|c|c|c|c|c|}
\hline & $\mathrm{N}$ & Years & Mean & SD & p5 & p50 & p95 \\
\hline Unemployment rate & 1879 & 1976-2012 & 6.1 & 2.1 & 3.2 & 5.7 & 10.1 \\
\hline Employment growth & 1777 & $1977-2012$ & 1.3 & 2.0 & -2.0 & 1.3 & 4.5 \\
\hline Participation rate & 1879 & $1976-2012$ & 66.3 & 4.1 & 59.6 & 66.6 & 72.6 \\
\hline Population growth $1 /$ & 1777 & $1977-2012$ & 1.3 & 1.2 & -0.1 & 1.1 & 3.4 \\
\hline Predicted employment growth (imix) & 1828 & $1976-2012$ & 1.8 & 1.8 & -0.8 & 2.2 & 4.9 \\
\hline \multicolumn{8}{|l|}{ Employment share in } \\
\hline oil\&gas industries & 1804 & $1976-2011$ & 0.7 & 1.5 & 0.0 & 0.1 & 4.0 \\
\hline Net migration rate & 1064 & $1990-2012$ & 0.1 & 1.0 & -1.2 & 0.1 & 1.7 \\
\hline Net migration rate (ACS) & 255 & $2007-2011$ & 0.0 & 1.1 & -1.0 & 0.2 & 1.1 \\
\hline Retail sales per capita 2/ & 1785 & $1970-2005$ & 6854.4 & 3832.5 & 1949.6 & 6248.9 & 13828.5 \\
\hline Annual growth in RSPC & 1683 & $1971-2005$ & 6.0 & 5.5 & -1.9 & 5.5 & 15.2 \\
\hline State GDP per capita 2/ & 1836 & $1970-2005$ & 20842.5 & 13820.8 & 5092.4 & 18868.6 & 41962.6 \\
\hline Annual growth in GSPPC & 1785 & $1971-2005$ & 6.5 & 4.4 & 0.8 & 6.0 & 12.9 \\
\hline
\end{tabular}

1/ civilian non-institutional population 16 years and older $2 /$

in current USD

Notes: The mean, standard deviation (SD) and the 5th (p5), median (p50), and 95th (p95) percentiles are shown for each variable, over all years and all states. State-level labor market variables are taken from the Local Area Unemployment Statistics (LAUS) of the BLS. Predicted employment growth and employment share in each industry is constructed using the BEA's Regional Economic Information System (REIS) dataset. Net migration rate starting in 1990 is for all ages and taken from the Bureau of the Census Population Estimate Program. Net migration rate (ACS) is for 16-65 years old and from the American Community Survey database. State-level retail sales data are taken from Zhou(2010) and not available for 1999 . 
Table 2. Employment Shares by Industry across U.S. States in 2012

2012 NAICS industry:

2012

\begin{tabular}{|c|c|c|c|c|c|}
\hline & Mean & SD & Min & Median & Max \\
\hline \multirow[t]{2}{*}{ Accommodation and food services } & $8.9 \%$ & $2.3 \%$ & $6.7 \%$ & $8.3 \%$ & $21.9 \%$ \\
\hline & & & Connecticut & Texas & Nevada \\
\hline \multirow[t]{2}{*}{ Administrative and waste mgt. serv. } & $6.8 \%$ & $1.3 \%$ & $4.2 \%$ & $6.8 \%$ & $9.2 \%$ \\
\hline & & & North Dakota & Kansas & Arizona \\
\hline \multirow[t]{2}{*}{ Arts, entertainment, \& recreation } & $2.6 \%$ & $0.5 \%$ & $1.5 \%$ & $2.5 \%$ & $3.8 \%$ \\
\hline & & & Arkansas & Pennsylvania & Montana \\
\hline \multirow[t]{2}{*}{ Construction } & $6.2 \%$ & $1.2 \%$ & $2.8 \%$ & $6.2 \%$ & $9.6 \%$ \\
\hline & & & District of Columbia & Tennessee & Wyoming \\
\hline \multirow[t]{2}{*}{ Durable goods manufacturing } & $5.1 \%$ & $2.4 \%$ & $0.1 \%$ & $5.1 \%$ & $11.3 \%$ \\
\hline & & & District of Columbia & Missouri & Indiana \\
\hline \multirow[t]{2}{*}{ Educational services } & $2.7 \%$ & $1.4 \%$ & $1.0 \%$ & $2.3 \%$ & $9.2 \%$ \\
\hline & & & Nevada & South Dakota & District of Columbia \\
\hline \multirow[t]{2}{*}{ Finance and insurance } & $6.2 \%$ & $1.6 \%$ & $3.8 \%$ & $5.9 \%$ & $11.8 \%$ \\
\hline & & & Alaska & Ohio & Delaware \\
\hline \multirow[t]{2}{*}{ Forestry, fishing, \& related activities } & $0.7 \%$ & $0.6 \%$ & $0.0 \%$ & $0.5 \%$ & $3.1 \%$ \\
\hline & & & District of Columbia & Oklahoma & Alaska \\
\hline \multirow[t]{2}{*}{ Health care and social assistance } & $13.2 \%$ & $1.9 \%$ & $8.5 \%$ & $13.2 \%$ & $16.9 \%$ \\
\hline & & & Nevada & New Hampshire & West Virginia \\
\hline \multirow[t]{2}{*}{ Information } & $2.0 \%$ & $0.5 \%$ & $1.3 \%$ & $1.8 \%$ & $3.7 \%$ \\
\hline & & & Mississippi & Illinois & Washington \\
\hline \multirow[t]{2}{*}{ Mgt. of companies \& enterprises } & $1.3 \%$ & $0.5 \%$ & $0.4 \%$ & $1.2 \%$ & $2.5 \%$ \\
\hline & & & Wyoming & New Hampshire & Minnesota \\
\hline \multirow[t]{2}{*}{ Mining } & $1.3 \%$ & $2.2 \%$ & $0.1 \%$ & $0.4 \%$ & $10.8 \%$ \\
\hline & & & Massachusetts & Virginia & Wyoming \\
\hline \multirow[t]{2}{*}{ Nondurable goods manufacturing } & $3.2 \%$ & $1.3 \%$ & $0.2 \%$ & $3.2 \%$ & $6.2 \%$ \\
\hline & & & District of Columbia & New Jersey & Arkansas \\
\hline \multirow[t]{2}{*}{ Other services, except public admin. } & $6.8 \%$ & $1.1 \%$ & $5.3 \%$ & $6.6 \%$ & $13.2 \%$ \\
\hline & & & Nevada & Nebraska & District of Columbia \\
\hline \multirow[t]{2}{*}{ Professional, scientific \& technical } & $7.5 \%$ & $2.8 \%$ & $4.4 \%$ & $7.1 \%$ & $21.9 \%$ \\
\hline & & & South Dakota & Alaska & District of Columbia \\
\hline \multirow[t]{2}{*}{ Real estate and rental and leasing } & $5.1 \%$ & $1.2 \%$ & $3.3 \%$ & $4.9 \%$ & $8.1 \%$ \\
\hline & & & Iowa & Alabama & Arizona \\
\hline \multirow[t]{2}{*}{ Retail trade } & $12.3 \%$ & $1.6 \%$ & $3.9 \%$ & $12.4 \%$ & $15.2 \%$ \\
\hline & & & District of Columbia & Washington & New Hampshire \\
\hline \multirow[t]{2}{*}{ Transportation and warehousing } & $3.8 \%$ & $1.0 \%$ & $1.2 \%$ & $3.6 \%$ & $6.8 \%$ \\
\hline & & & District of Columbia & Idaho & Alaska \\
\hline \multirow[t]{2}{*}{ Utilities } & $0.4 \%$ & $0.2 \%$ & $0.1 \%$ & $0.4 \%$ & $0.8 \%$ \\
\hline & & & Tennessee & Iowa & Wyoming \\
\hline \multirow[t]{2}{*}{ Wholesale trade } & $3.9 \%$ & $0.8 \%$ & $1.0 \%$ & $3.9 \%$ & $6.0 \%$ \\
\hline & & & District of Columbia & Pennsylvania & North Dakota \\
\hline
\end{tabular}

Source: Regional Economic Information System from the BEA. 
Table 3. Endogeneity and 2SLS: Employment Rate (le) Equation

\begin{tabular}{ll|lll}
\hline & OLS & \multicolumn{3}{|c}{ 2SLS } \\
\hline$\Delta \ln \left(e_{t}\right)$ & ).241*** & $0.656^{* *}$ & $0.438^{* *}$ & $0.645^{* *}$ \\
& $(0.023)$ & $*$ & $*$ & $*$ \\
Hausman test (p) & 0.00 & 0.07 & 0.00 & 0.00 \\
\hline 1st Stage & & & \\
imix & & $0.88^{* * *}$ & & $0.776^{* *}$ \\
& & $(0.118)$ & & $(0.146)$ \\
oil & & & $0.405^{* *}$ & $0.283^{* *}$ \\
& & & $(0.087)$ & $(0.087)$ \\
F stat & & 55.76 & 21.38 & 31.29 \\
$\mathrm{~N}$ & & 1683 & 1460 & 1409 \\
\hline
\end{tabular}

Note: The instruments imix and oil are as defined in equations 3 and 4 in the text. Robust standard errors in parenthesis. All regressions also include the set of lagged variables as in each equation of the system in 1 as well as state and time fixed effects.

Table 4. Endogeneity and 2SLS: Participation Rate (lp) Equation

\begin{tabular}{|c|c|c|c|c|}
\hline & OLS & & $2 \mathrm{SLS}$ & \\
\hline$\Delta \ln \left(e_{t}\right)$ & $\begin{array}{l}) .387 * * * \\
(0.025)\end{array}$ & $\begin{array}{l}0.154^{*} \\
(0.084)\end{array}$ & $\begin{array}{l}0.380 * * * \\
(0.116)\end{array}$ & $\begin{array}{l}0.180 * * * \\
(0.077)\end{array}$ \\
\hline Hausman test (p) & & 0.00 & 0.78 & 0.00 \\
\hline \multicolumn{5}{|l|}{ 1st Stage } \\
\hline imix & & $\begin{array}{l}0.88 * * * \\
(0.118)\end{array}$ & & $\begin{array}{l}0.776^{* * *} \\
(0.146)\end{array}$ \\
\hline oil & & & $\begin{array}{l}0.405 * * * \\
(0.087)\end{array}$ & $\begin{array}{l}0.283 * * * \\
(0.087)\end{array}$ \\
\hline F stat & & 55.76 & 21.38 & 31.29 \\
\hline $\mathrm{N}$ & 1736 & 1683 & 1460 & 1409 \\
\hline
\end{tabular}

Note: The instruments imix and oil are as defined in equations 3 and 4 in the text. Robust standard errors in parenthesis. All regressions also include the set of lagged variables as in each equation of the system in 1 as well as state and time fixed effects. 
Table 5. Direct Estimation of Migration Response to Labor Market Shocks using ACS Data

\begin{tabular}{ccc|cc}
\hline Dependent variable: & \multicolumn{5}{c}{ ACS migration rate } \\
& OLS & GLS & OLS & GLS \\
& $(1)$ & $(2)$ & $(3)$ & $(4)$ \\
\hline imix $_{s, t}$ & -0.186 & -0.199 & - & - \\
& $(0.178)$ & $(0.156)$ & & \\
imix $_{s, t-1}$ & $0.338^{* *}$ & $0.402^{* *}$ & - & - \\
$\Delta e_{s, t}$ & $(0.142)$ & $(0.166)$ & & \\
& - & - & $0.092^{* *}$ & $0.182^{* * *}$ \\
$\Delta e_{s, t-1}$ & & & $(0.034)$ & $(0.049)$ \\
& - & - & -0.025 & -0.366 \\
$H_{0}:$ cum. $\Delta \ln P$ op $=V A R$ & & & $(0.028)$ & $(0.043)$ \\
$(\mathrm{p}-\mathrm{val})$ & & & & \\
$N$ & 0.18 & 0.40 & 0.00 & 0.00 \\
$R^{2}$ & 255 & 204 & 255 & 204 \\
& 0.07 & 0.09 & 0.06 & 0.09 \\
\hline
\end{tabular}

Note: ACS migration rates (measured as working-age net migrants/initial working-age population by state) are detrended using state-specific linear trends. Robust standard errors in parenthesis. All regressions also include a set of state and time fixed effects. Column (3) and (4) also include $l e_{s, t-1}$ and $l p_{s, t-1}$. The p-values derive from a Wald test that the cumulative effect of 1 percent labor demand shock on population change is equal to the one obtained under the corresponding VAR model. 
Table 6: Job-Related Out-migration Rate by State during the Great Recession: percent of working-age labor force overall and percent of unemployed (ordered by cumulative out-migration rate, second column)

\begin{tabular}{|c|c|c|c|}
\hline State & 2008-2009 & cum. 2007-2010 & $\begin{array}{l}\text { cum. 2007-2010 } \\
\text { (if unemployed) }\end{array}$ \\
\hline Idaho & 0.45 & 2.15 & 4.39 \\
\hline Nevada & 1.05 & 1.56 & 11.90 \\
\hline Alaska & 0.46 & 1.19 & 0.00 \\
\hline West Virginia & 1.16 & 1.07 & 8.07 \\
\hline Hawaii & 0.69 & 0.76 & 10.09 \\
\hline Oregon & 0.19 & 0.71 & 4.61 \\
\hline Iowa & 0.00 & 0.70 & 2.34 \\
\hline Florida & 0.36 & 0.70 & 4.98 \\
\hline Colorado & 0.25 & 0.67 & 2.08 \\
\hline Rhode Island & 0.00 & 0.65 & 6.07 \\
\hline Tennessee & 0.17 & 0.61 & 3.45 \\
\hline Maine & 0.00 & 0.61 & 0.00 \\
\hline Vermont & 0.36 & 0.60 & 2.39 \\
\hline Mississippi & 0.00 & 0.59 & 0.00 \\
\hline Alabama & 0.18 & 0.52 & 2.79 \\
\hline Oklahoma & 0.25 & 0.51 & 3.11 \\
\hline Washington & 0.02 & 0.51 & 1.81 \\
\hline Montana & 0.19 & 0.49 & 0.00 \\
\hline California & 0.21 & 0.43 & 2.21 \\
\hline Utah & 0.08 & 0.43 & 5.26 \\
\hline Illinois & 0.18 & 0.43 & 1.73 \\
\hline Virginia & 0.27 & 0.42 & 3.21 \\
\hline Texas & 0.10 & 0.37 & 2.97 \\
\hline New Mexico & 0.00 & 0.34 & 2.96 \\
\hline North Carolina & 0.03 & 0.34 & 1.01 \\
\hline Indiana & 0.15 & 0.32 & 1.59 \\
\hline Arizona & 0.02 & 0.32 & 2.97 \\
\hline Michigan & 0.13 & 0.31 & 0.79 \\
\hline Connecticut & 0.24 & 0.31 & 0.74 \\
\hline Georgia & 0.24 & 0.28 & 1.13 \\
\hline Maryland & 0.00 & 0.27 & 2.67 \\
\hline Wyoming & 0.00 & 0.27 & 2.60 \\
\hline Wisconsin & 0.02 & 0.25 & 0.00 \\
\hline Ohio & 0.07 & 0.25 & 0.94 \\
\hline New York & 0.11 & 0.25 & 1.48 \\
\hline New Jersey & 0.13 & 0.23 & 2.33 \\
\hline Minnesota & 0.03 & 0.21 & 2.84 \\
\hline Massachusetts & 0.11 & 0.19 & 1.73 \\
\hline Arkansas & 0.00 & 0.19 & 2.30 \\
\hline Pennsylvania & 0.07 & 0.19 & 1.78 \\
\hline Kentucky & 0.00 & 0.18 & 0.00 \\
\hline Missouri & 0.00 & 0.13 & 0.66 \\
\hline South Carolina & 0.00 & 0.12 & 0.53 \\
\hline Louisiana & 0.11 & 0.11 & 1.27 \\
\hline New Hampshire & 0.08 & 0.07 & 0.90 \\
\hline Nebraska & 0.05 & 0.04 & 0.00 \\
\hline Delaware & 0.00 & 0.00 & 0.00 \\
\hline Kansas & 0.00 & 0.00 & 0.00 \\
\hline North Dakota & 0.00 & 0.00 & 0.00 \\
\hline South Dakota & 0.00 & 0.00 & 0.00 \\
\hline
\end{tabular}

Source: Authors' calculations from the CPS March- supplements, various years. 
Table 7. Job-search Related Interstate Migration Rate of the Labor Force (in percent).

\begin{tabular}{|c|c|c|c|c|c|}
\hline $\begin{array}{l}\text { Employment status in } \\
\text { reference year: }\end{array}$ & $\begin{array}{l}\text { 1999-2012 } \\
\text { average }\end{array}$ & $\begin{array}{l}2006-2007 \\
\text { benchmark }\end{array}$ & $\begin{array}{l}2007-2008 \\
(2006-2007=100)\end{array}$ & $\begin{array}{l}2008-2009 \\
(2006-2007=100)\end{array}$ & $\begin{array}{l}2009-2010 \\
(2006-2007=100)\end{array}$ \\
\hline & 0.13 & 0.10 & 0.10 & 0.15 & 0.14 \\
\hline & & 100 & 106 & 154 & 147 \\
\hline \multirow[t]{2}{*}{$\begin{array}{l}\text { Unemployed: } \\
\text { partly unemployed }\end{array}$} & 0.62 & 0.65 & 0.50 & 0.61 & 0.39 \\
\hline & & 100 & 76 & 93 & 60 \\
\hline \multirow[t]{2}{*}{ all year unemployed } & 0.77 & 0.29 & 0.60 & 0.73 & 0.80 \\
\hline & & 100 & 206 & 252 & 276 \\
\hline \multicolumn{6}{|l|}{ Labor market entrant: } \\
\hline \multirow[t]{2}{*}{ partly NILF $1 /$} & 0.18 & 0.11 & 0.12 & 0.18 & 0.30 \\
\hline & & 100 & 111 & 167 & 280 \\
\hline \multirow[t]{2}{*}{ all year NILF 2/ } & 0.24 & 0.27 & 0.12 & 0.52 & 0.10 \\
\hline & & 100 & 46 & 192 & 36 \\
\hline \multicolumn{6}{|l|}{ Employed: } \\
\hline \multirow{2}{*}{ all year employed } & 0.05 & 0.03 & 0.05 & 0.05 & 0.05 \\
\hline & & 100 & 169 & 168 & 159 \\
\hline Counterfactual & & 0.10 & 0.10 & 0.11 & 0.13 \\
\hline
\end{tabular}

1/ Individuals who were never unemployed in the previous year, nor employed all year.

$2 /$ Individuals who did not work at all in the reference year because they were not in the labor force (NILF) and are in the labor force at the time of survey.

Notes: Entries are weighted percentages of respondents in the labor force between 16 and 65 years old who lived in a different state one year ago and moved "to find work or lost job", broken down by their employment status in the reference year of the move. Numbers in italics are standardized at 100 to the benchmark level in 2006-2007. Respondents with imputed migration data are excluded. Last row reports the counterfactual migration rate holding the within-group migration rates fixed at the benchmark (2006-2007) level, with only the employment status composition of the labor force changing as observed. Source: Authors' calculations from the CPS March supplements, various years. 
Figure 1. Persistence of Employment Growth Rates across US States, 1976-2011

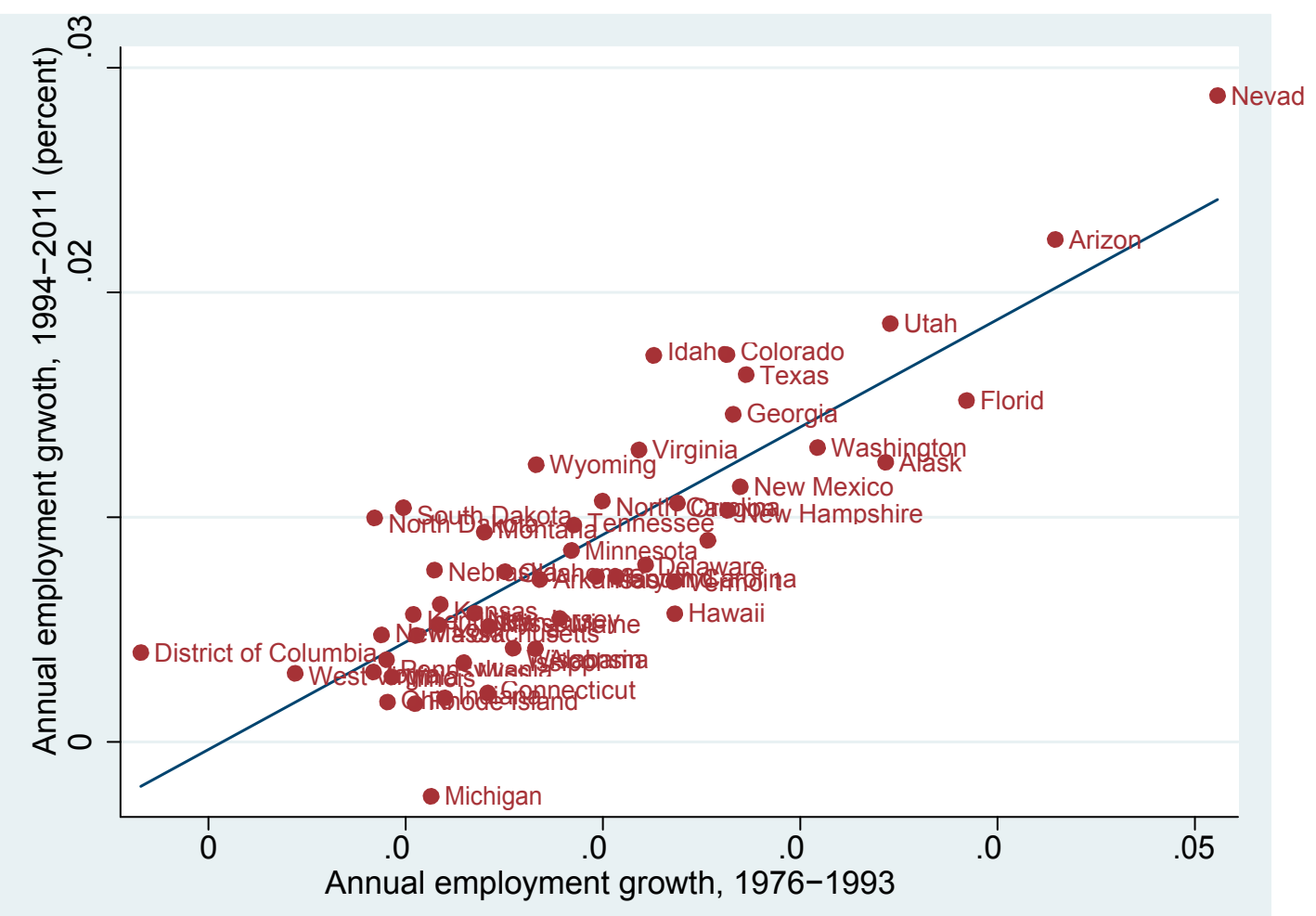

Sourc $\bar{\ominus}$. Authors' calculations based on data from the BLS Local Area Unemployment Statistics data. 
Figure 2. Dispersion of Employment Growth Rates across US States, 1976-2011

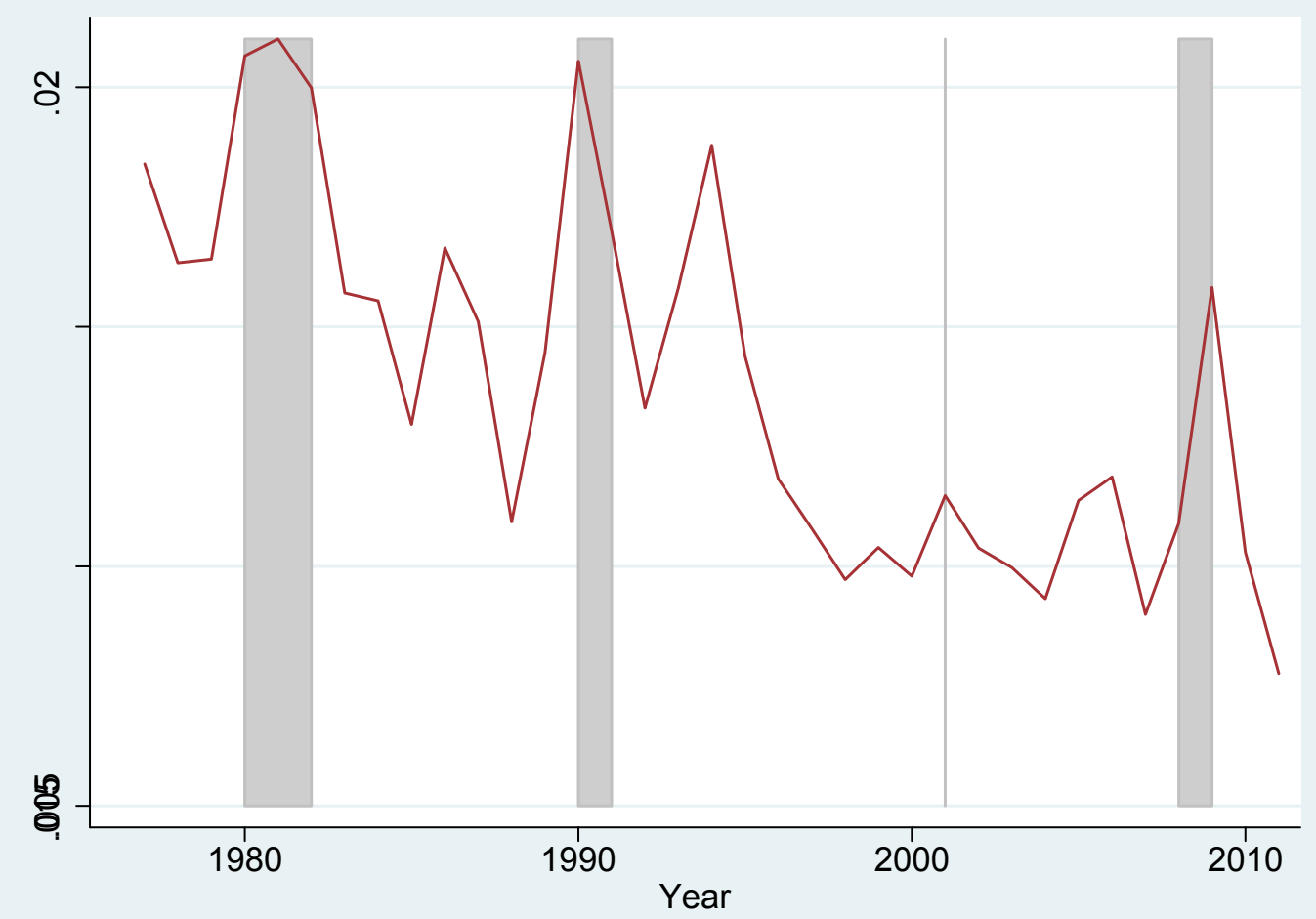

Source: Authors' calculations based on data from the BLS Local Area Unemployment Statistics data. Each year's data point corresponds to the standard deviation of employment growth rates across all US States. Shaded areas represent NBER recession years. 
Figure 3. Response of State-relative Labor Market Variables: OLS

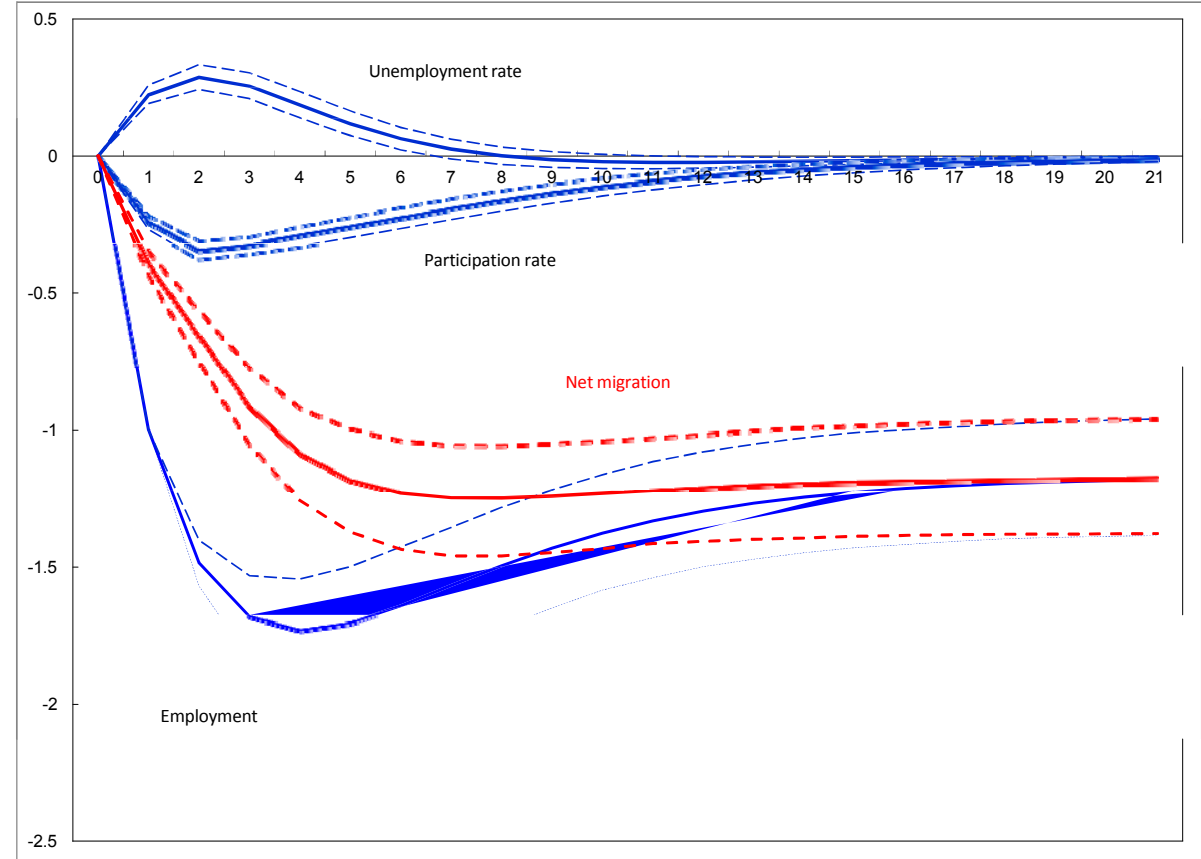

Source: Authors' calculations based on data from the BLS, estimates of system of panel VAR in (2). Confidence bands of 95 percent are bootstrapped with 500 replications. Units are percent deviation from pre-shock steady state. 
Figure 4. Distribution of Predicted Employment Growth Based on State-level Industry Mix
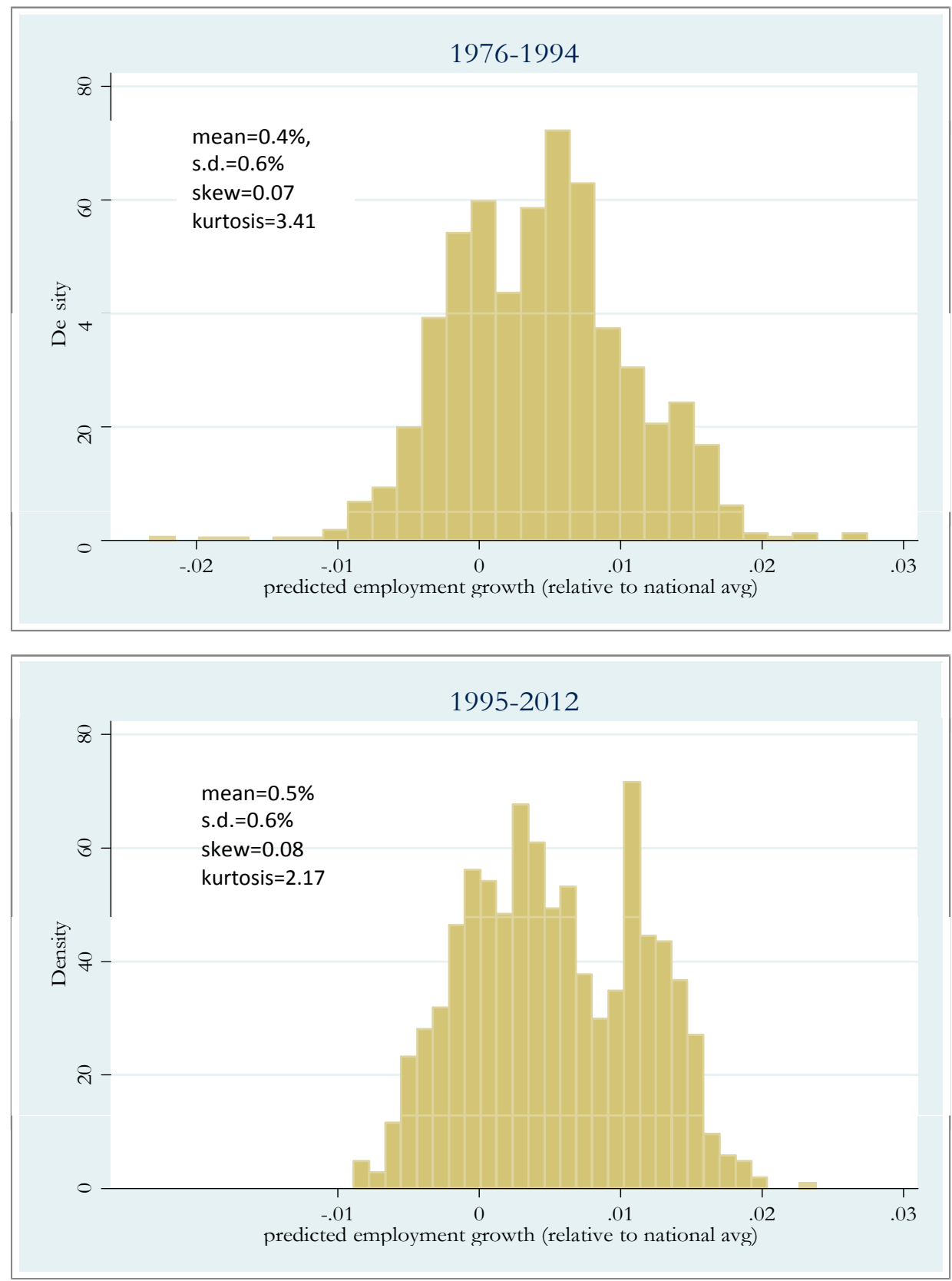
Figure 5. 2SLS First Stage Regression, Full Sample and Sub-samples
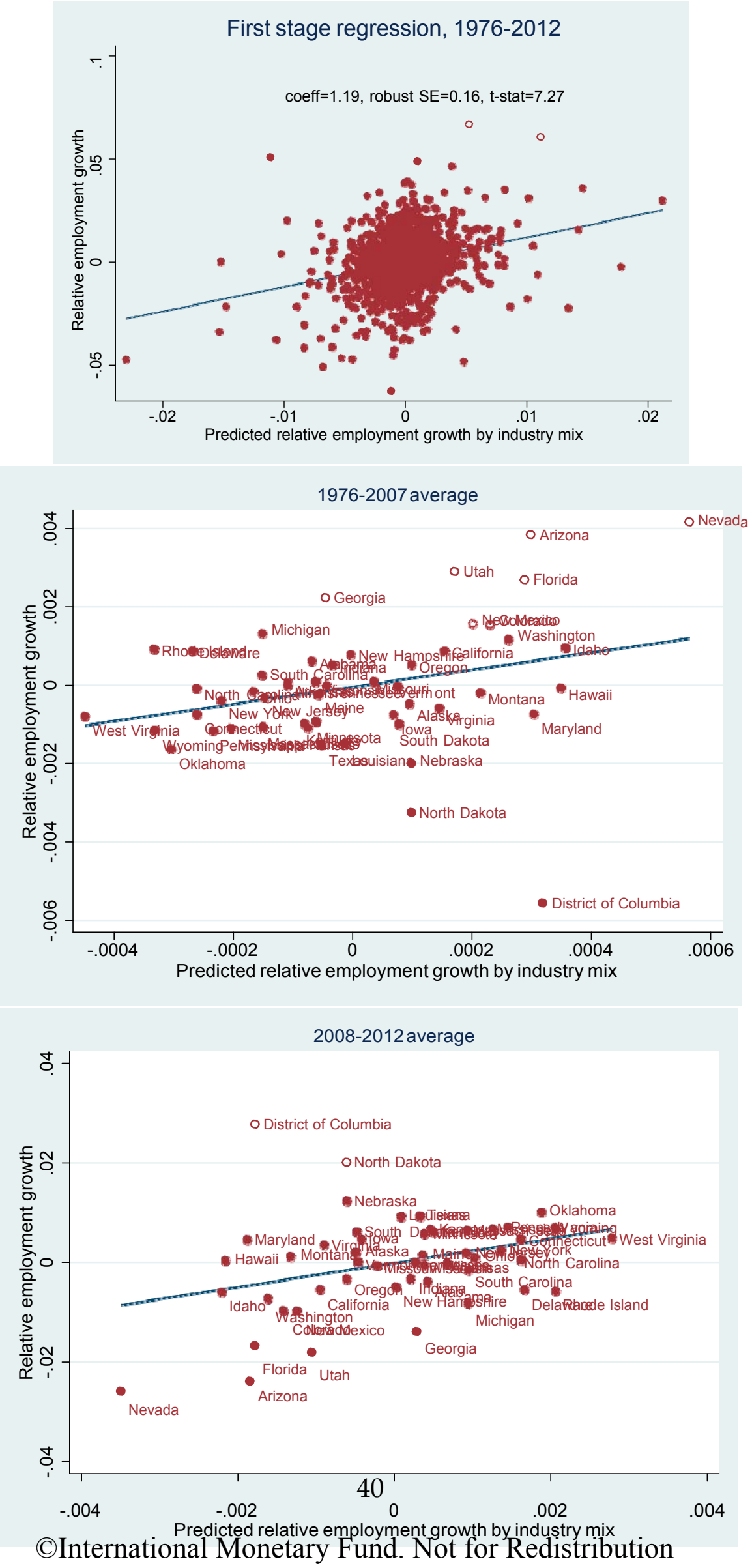
Figure 6. Response of State-relative Labor Market Variables: OLS vs. IV

Employment rate
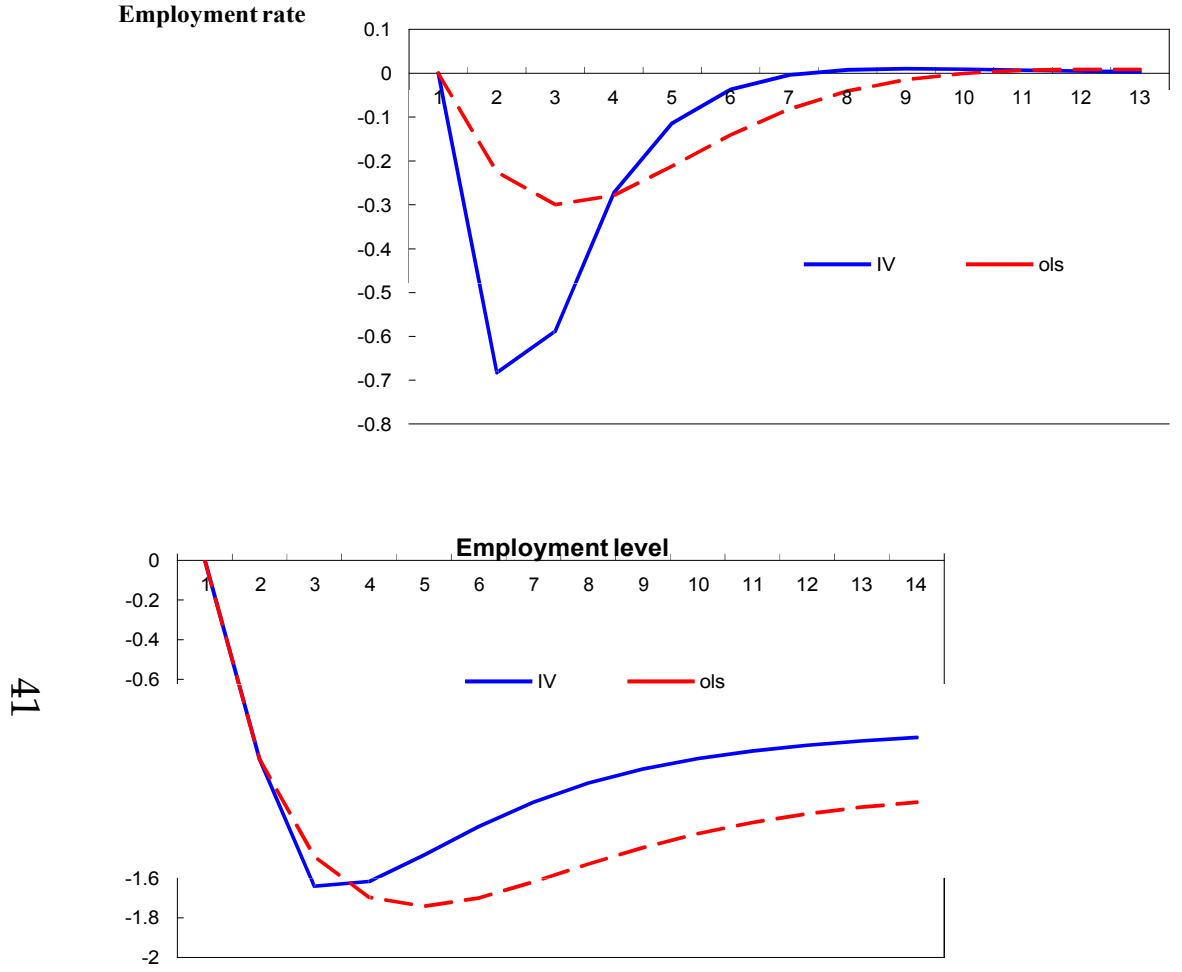

Participation rate

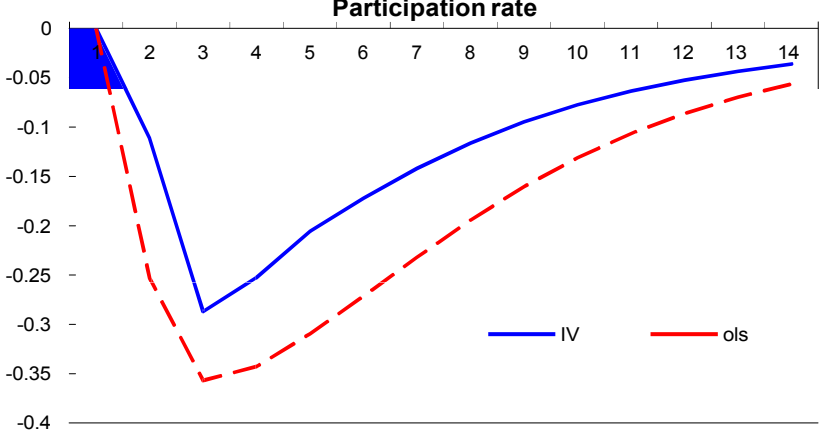

Migration

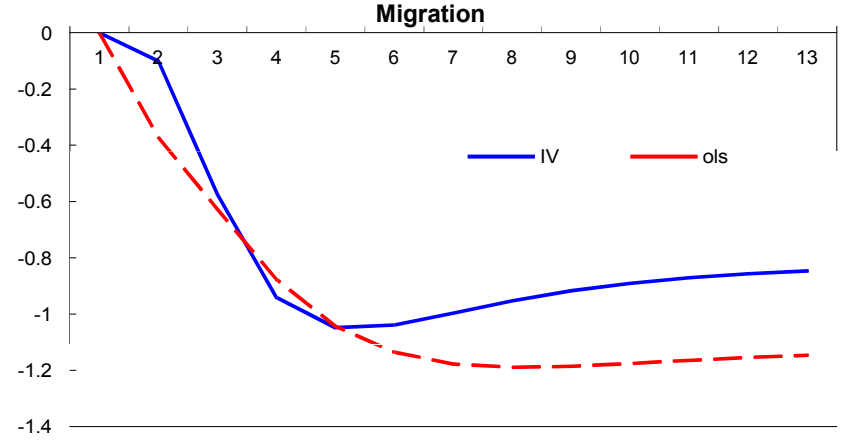

Note: Impulse response to 1 percent negative labor demand shock under OLS and reduced form using imix as IV. Units are percent deviation from pre-shock values. 
Figure 7. Decomposition of a 1 Worker Regional Labor Demand Shock to 3 Adjustment Margins: OLS vs. IV Reduced Form
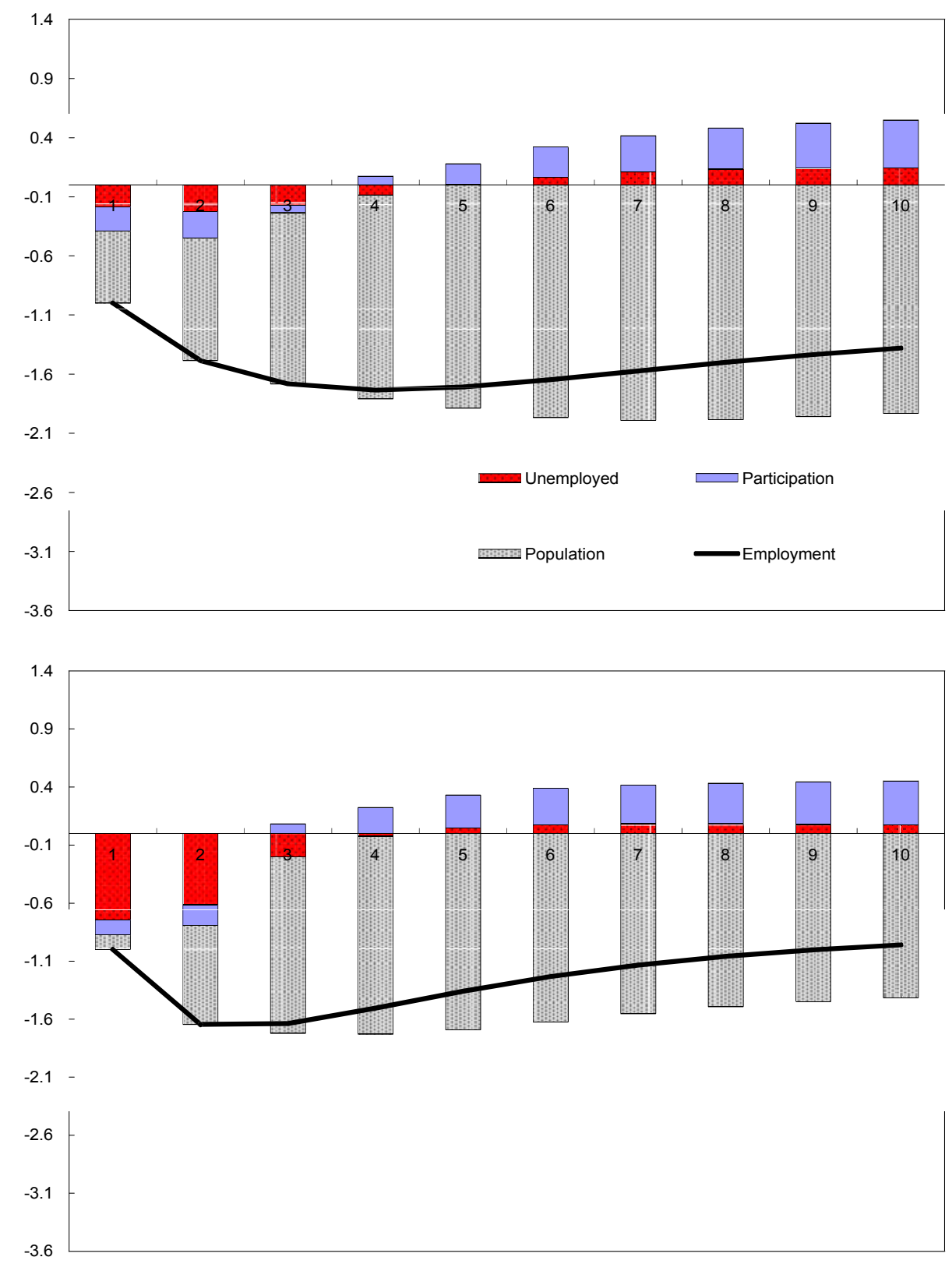

Decomposition derived from OLS estimation (upper chart) and reduced-form estimation with imix as instrumental variable (lower chart). Unit: number of workers. 
Figure 8. Response of Ccumulative Net Migration, Using Migration and Population Data Direct Estimates vs. VAR Identifications
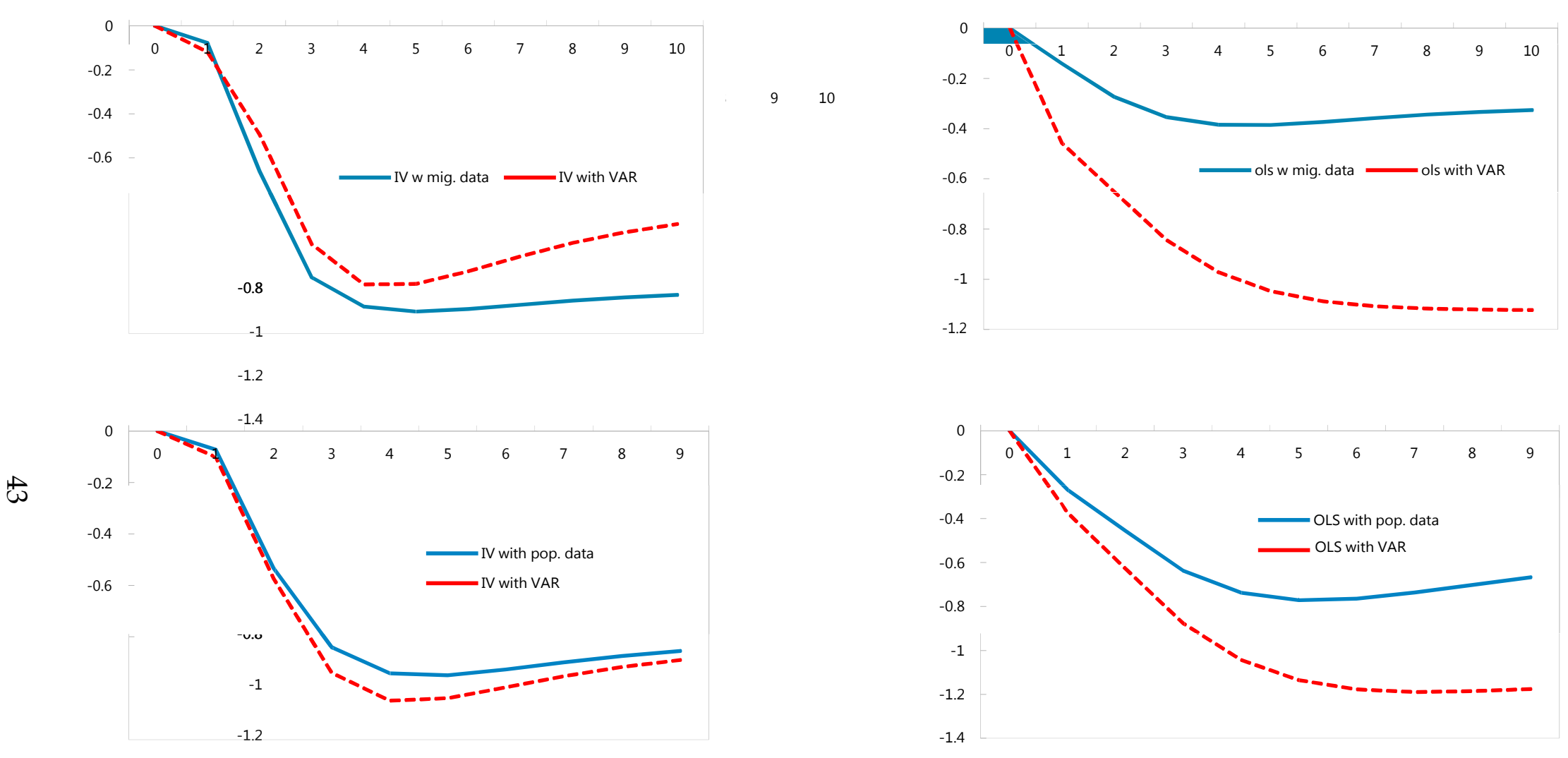

Notes: Sample period is 1991-2011 for migration data comparison (upper panel) and 1976-2011 for population data comparison. Horizontal axis denotes years after shock. Unit on vertical axis: percentage of civilian population. 
Figure 9. Response of Net Migration to 1 Percent State-relative Labor demand Shock: Three Sub-samples

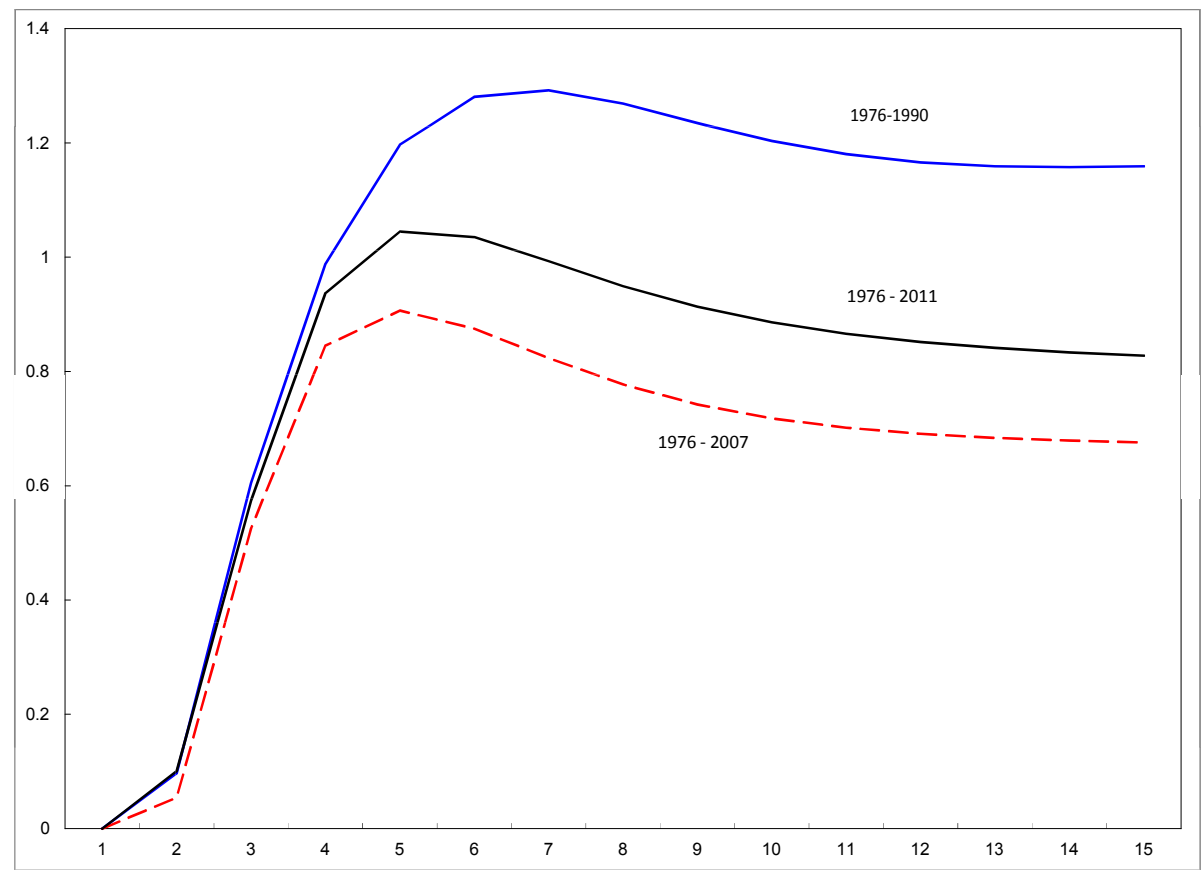


Figure 10: Cross-sectional Correlation between Labor Demand and Net-migration: 2007 vs. 2009.

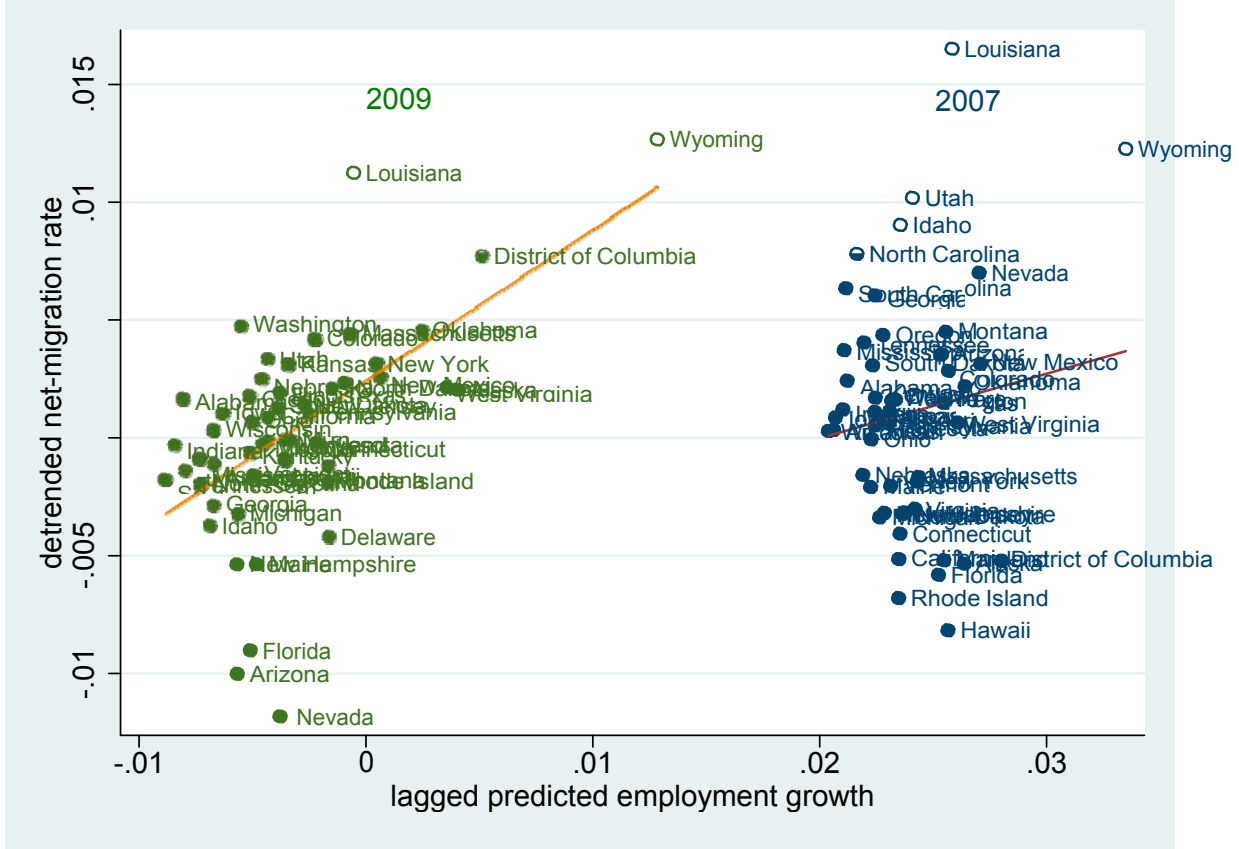

Note: predicted employment growth is the industry mix variable (imix) used as instrumental variable for statelevel labor demand as defined in equation 3 in the text. Net in-migration rates (in percent of state working-age population) are taken as deviations from state-specific linear trends. 
Figure 11. Short-run Response of Net Migration to Labor Demand Shock of 1 Worker: Expanding Window Regressions
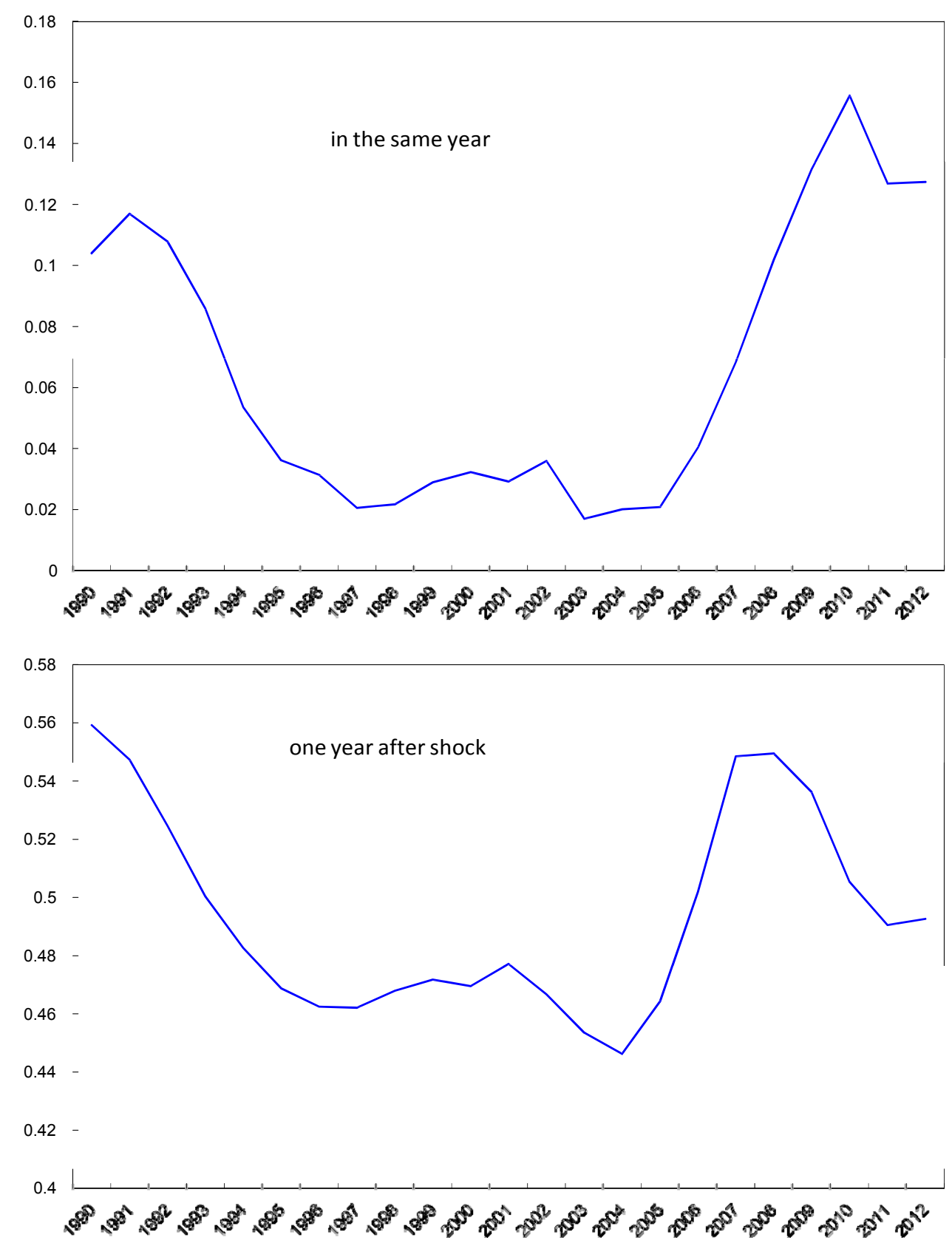

Horizontal axis denotes last year of observation in expanding window. Unit on vertical axis is number of net out/inmigrants for each job lost/gained. 
Figure 12. Short-run Response of Migration/unemployment/participation to Labor Demand Shock of 1 Worker: Expanding Window Regressions
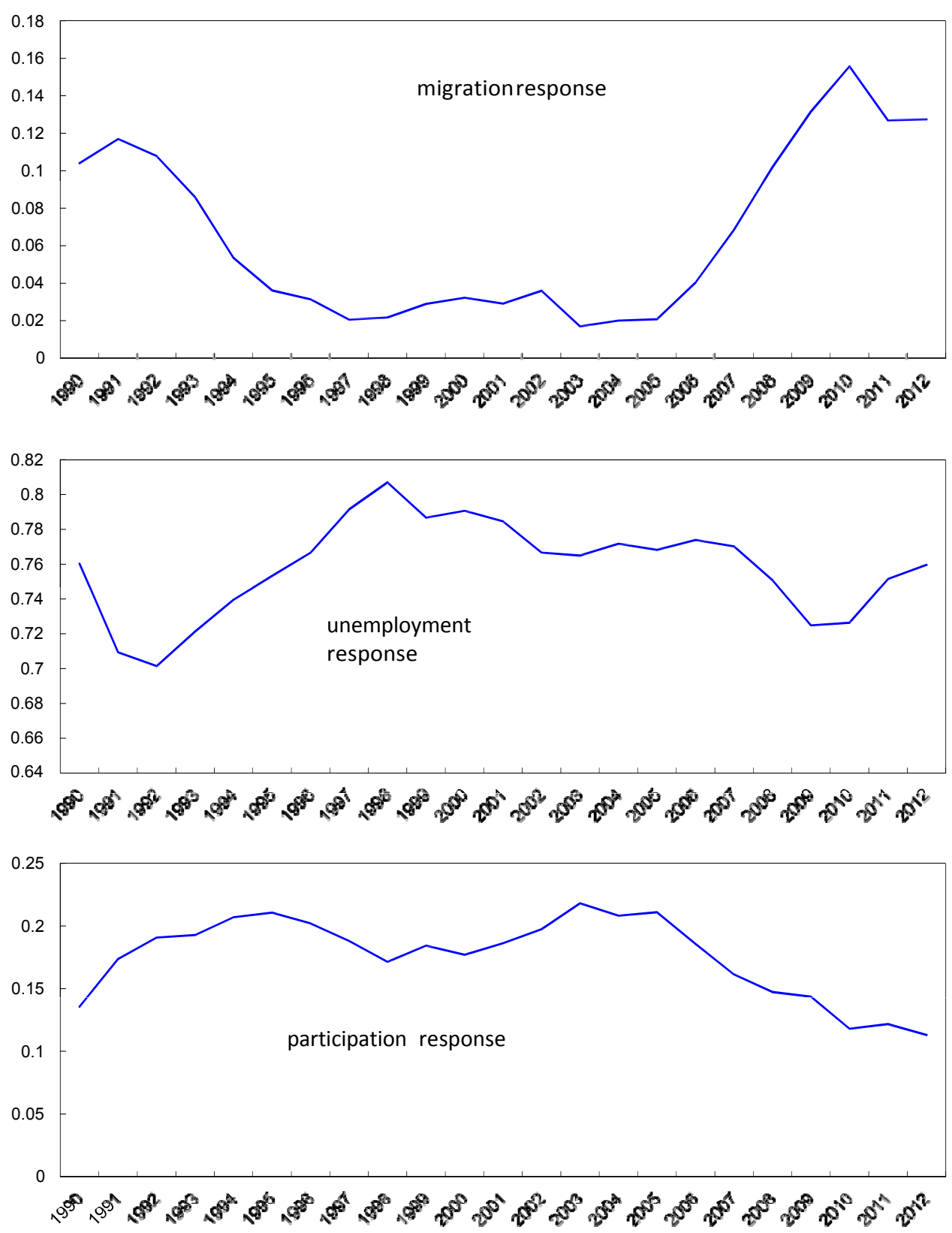

Horizontal axis denotes last year of observation in expanding window. Unit on vertical axis is share of adjustment through each margin for each job lost/gained. 
Figure 13. Interstate Migration Rate: Percent of Working-age Population

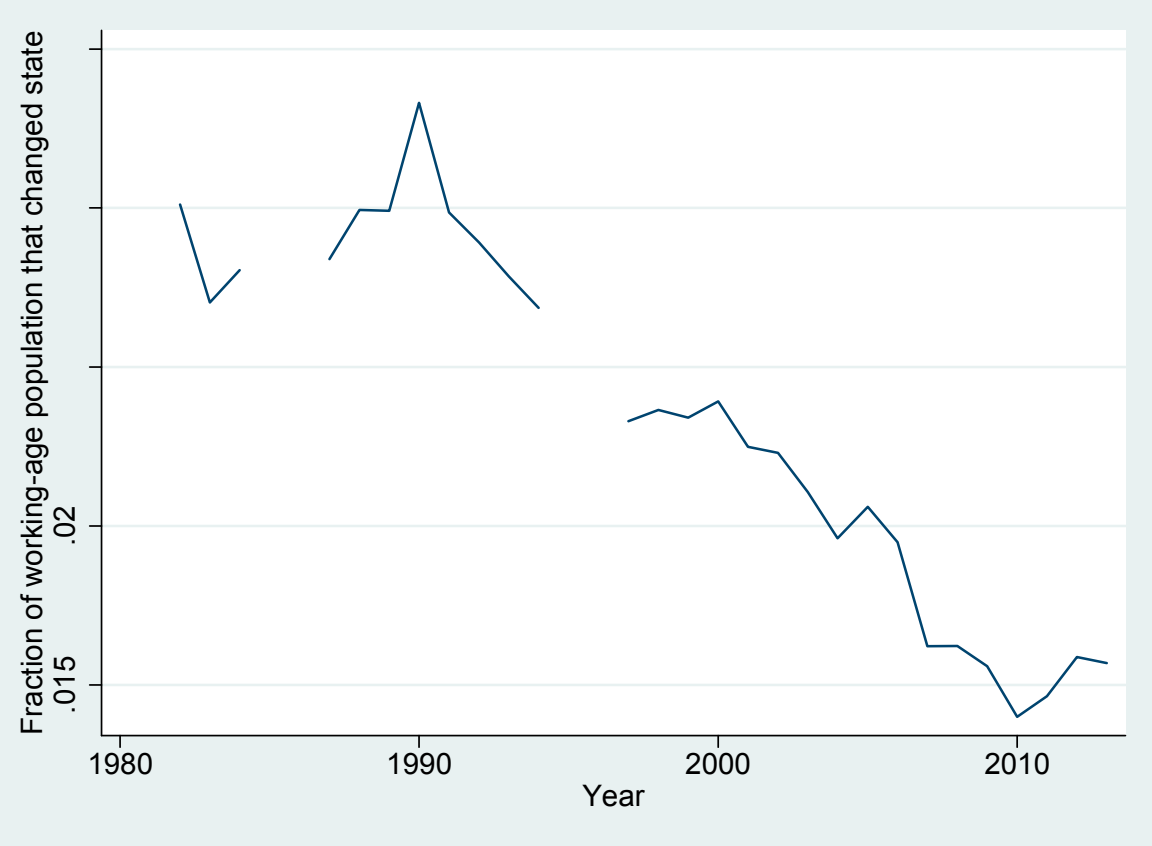

Source: Authors' calculation based on CPS March supplement micro data, 1980-2012. No migration question were asked in 1985 and 1995 CPS surveys. Respondents with imputed migration status were excluded from the computation starting 1996. 
Figure 14. Interstate Migration Rate for Job-search: Percent of Working-age Labor Force

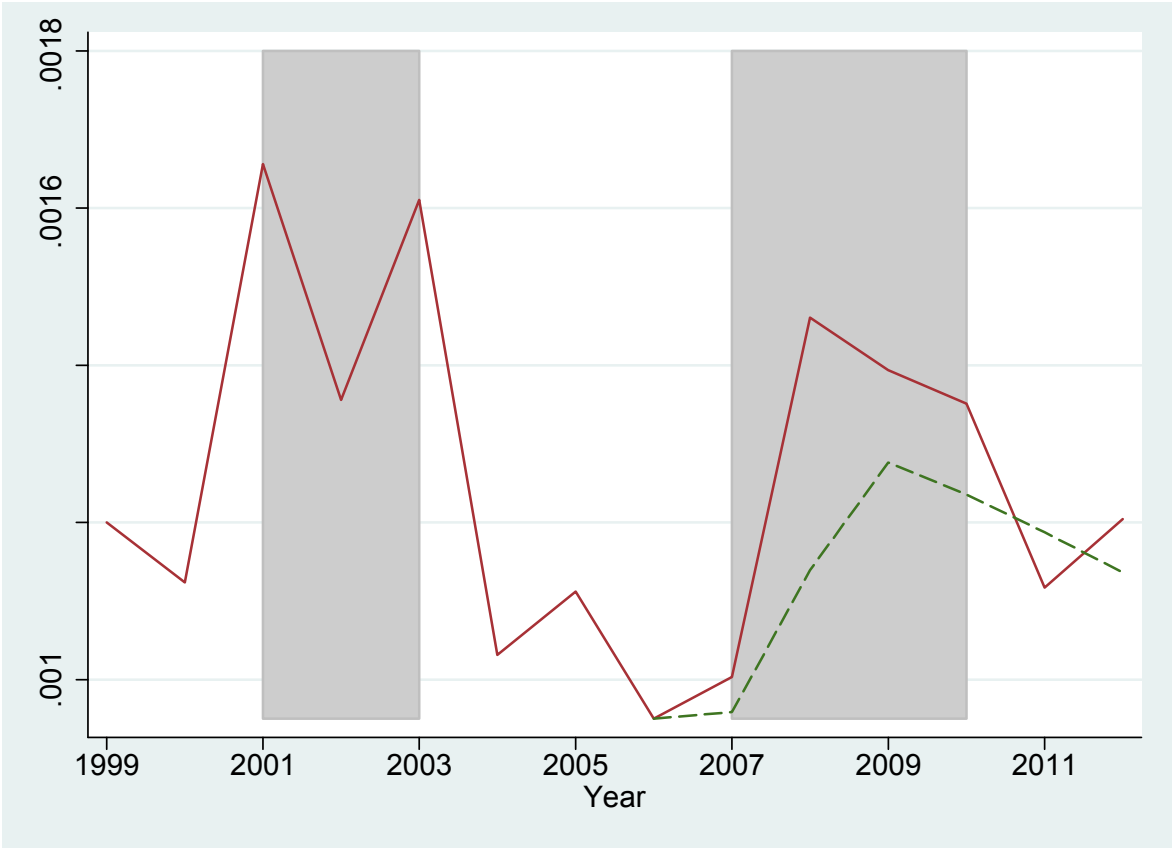

Source: Authors' calculation based on CPS March supplement micro data, 1999-2013. Respondents with imputed migration status were excluded from the computation starting 1996. Dashed green line is the counterfactual migration rate resulting from the shift share analysis in Table 7. Shaded areas include years between trough and peak of the unemployment rate around each re- cession. 
Figure 15. Response of State-level Relative Labor Market Variables to a 1 Percent Negative Labor Demand Shock: Business Cycle Interaction

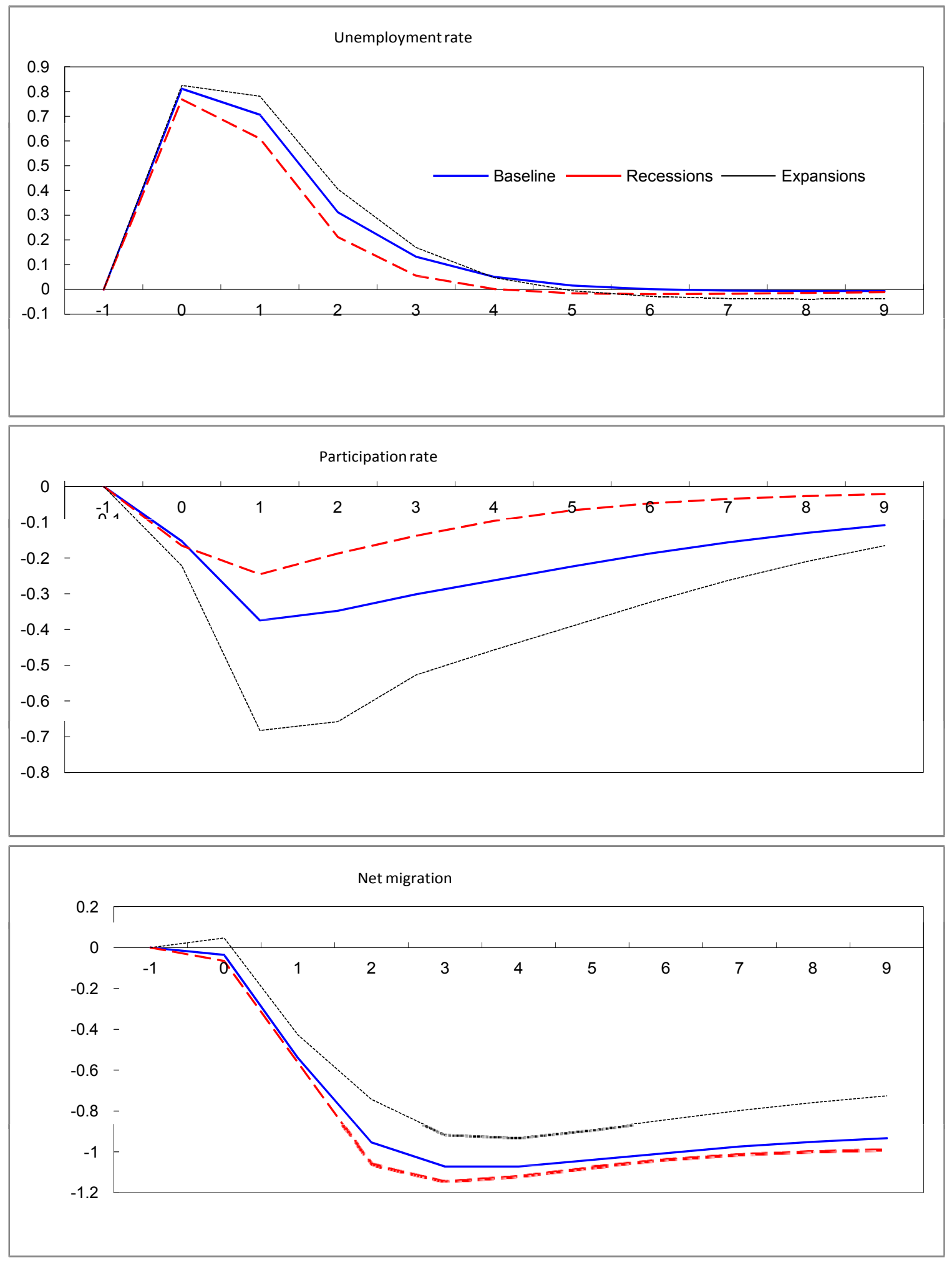


Figure 16. Response of Cumulative Net Migration to a 1 Percent Negative Labor Demand Shock: Business Cycle Interaction

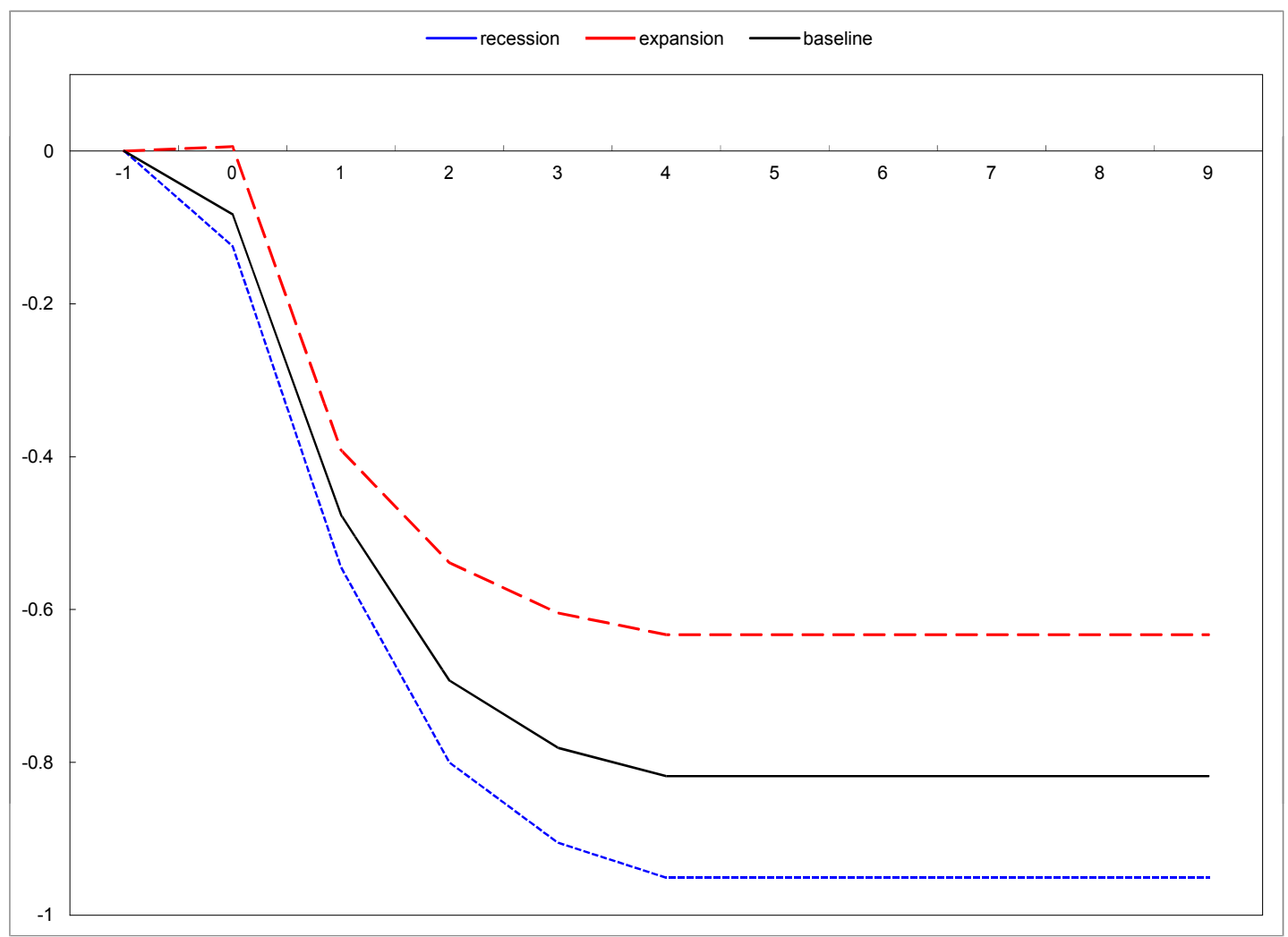

Note: Derived response is directly estimated according to equation 9 using state-level working-age population data. Units are percentage deviation from baseline level. 
Figure 17. Dynamics of Uninsured Risk: Business Cycle Interaction

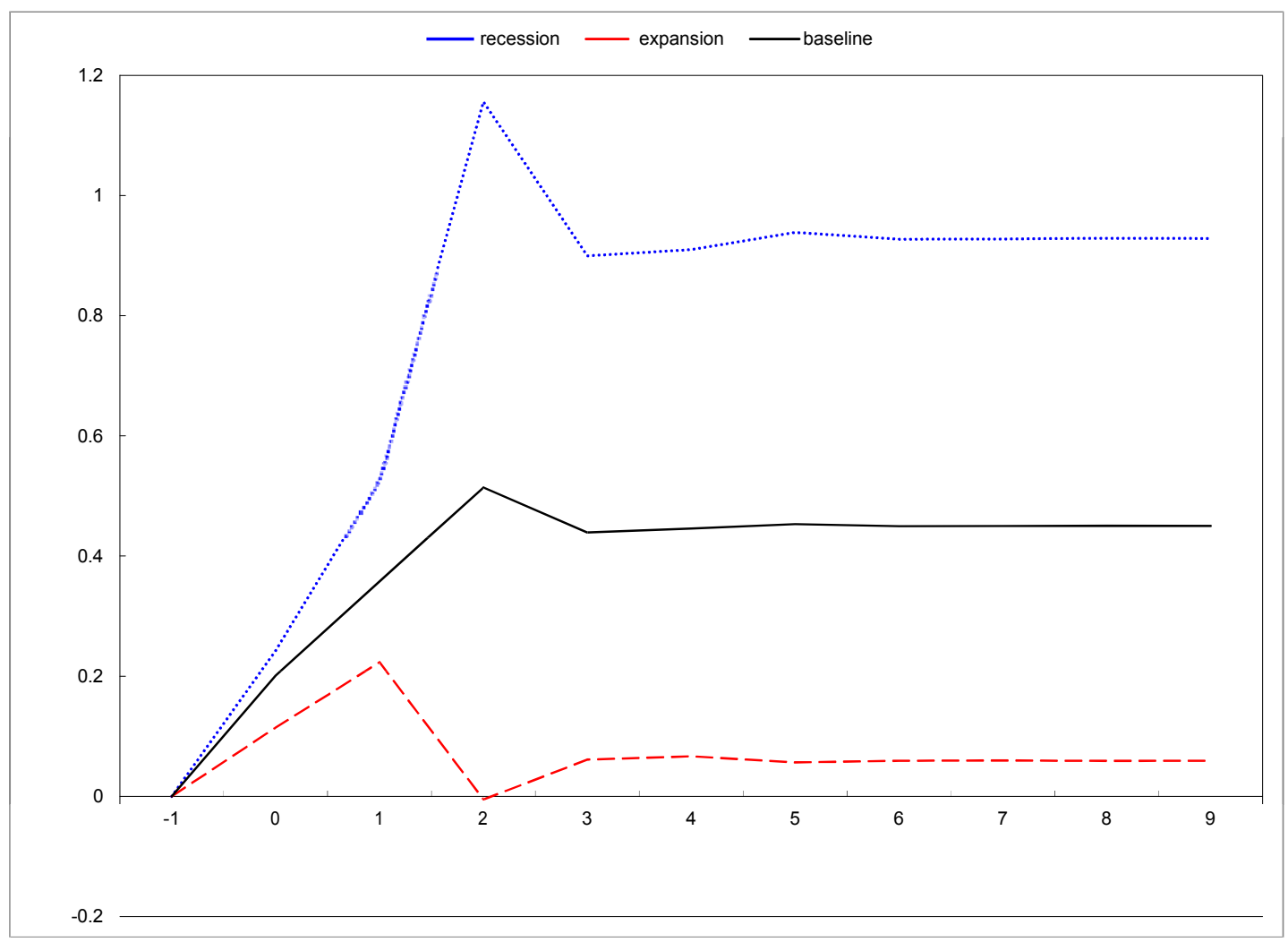

Note: Dynamic response of state consumption to 1 percent shock to state GDP. Estimates derived using equation 10 . 
Figure 18. Response of Cumulative Net Migration to a 1 Percent Negative Labor Demand Shock: Role of Risk Sharing
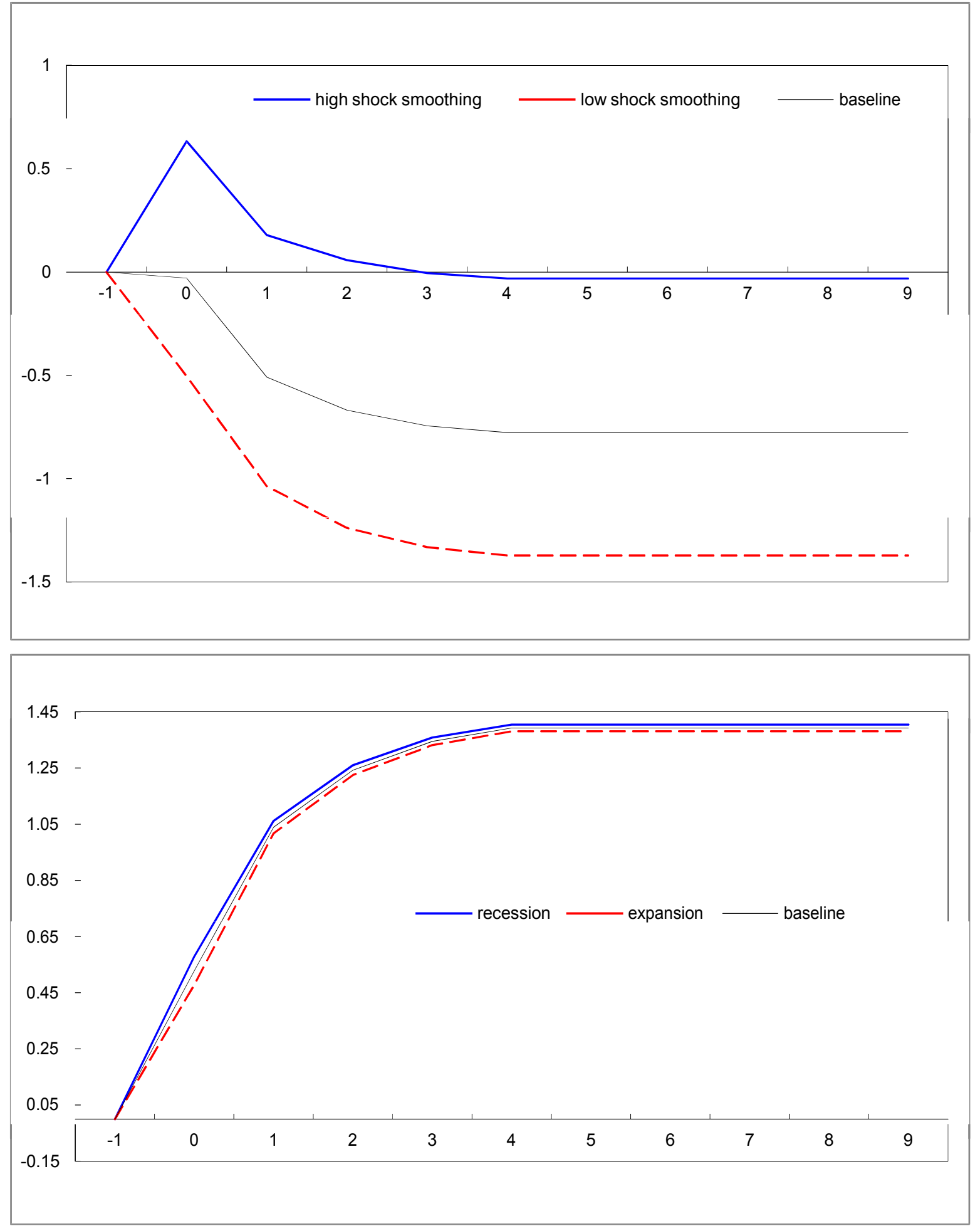

Note: Upper chart shows the response of net-migration to a 1 percent negative labor demand shock under the high and low shock-smoothing/risk sharing regimes (as well as the linear base- line). The lower chart shows the cyclical variation in migration response similar to Figure 16, but controlling for the degree of risk sharing. 